\title{
Groundwater Resources Management Modelling: A Review
}

\author{
Banjo A. Aderemi ${ }^{1, *}$, Thomas O. Olwal ${ }^{1}$, Julius M. Ndambuki ${ }^{2}$ and Sophia S. Rwanga ${ }^{3}$ \\ 1 Department of Electrical Engineering, Tshwane University of Technology Pretoria, South Africa; \\ ayoadebanjo93@hotmail.com (B.A.A.), OlwalTO@tut.ac.za (T.O.O.) \\ 2 Department of Civil Engineering, Tshwane University of Technology Pretoria, South Africa; \\ (NdambukiJM@tut.ac.za) \\ 3 Department of Civil Engineering, Vaal University of Technology Vanderbijlpark, South Africa; \\ (sophiar@vut.ac.za) \\ * Correspondence: ayoadebanjo93@hotmail.com; Tel.: +27783542284
}

\begin{abstract}
Globally, groundwater is the largest distributed storage of freshwater that plays an important role in an ecosystem's sustainability in addition to aiding human adaptation to both climatic change and variability. However, groundwater resources are dynamic and often changes as a result of land usage, abstraction as well as variation in climate. Thus, efficient management of groundwater resources to prevent overexploitation, scarcity, and minimising the effects of drought has become a major challenge for researchers as well as water managers. Furthermore, a number of research challenges such as the lack of computational efficiency and scalability due to uncertainties from input parameters to the groundwater resource model have been revealed in the management of groundwater resources. To solve these challenges, many conventional solutions such as numerical techniques have been proffered for groundwater modelling. Also, the use of data-driven techniques such as machine learning is gaining more attraction to solve these aforementioned challenges. Thus, this has made efficient data gathering essential to maintain data-driven groundwater resources management models from the observation site. The global evolution of the Internet of Things (IoTs), has increased the nature of data gathering for the management of groundwater resources. In addition, efficient data-driven groundwater resource management relies hugely on information relating to changes in groundwater resources as well as their availability. Although the IoTs enabled automated data processing systems are in existence by transmitting the generated data from IoT enabled devices into the cloud through the Internet. However, traditional IoT Internet is not scalable and efficient enough to process the generated vast IoT data At the moment, some pieces of the literature revealed the groundwater managers lack an efficient, scalable and real-time groundwater management system to gather the required data. Also, the literature revealed that the existing methods of collecting data lack efficiency to meet computational model requirements and meet management objectives. Thus, it is necessary to have an efficient and scalable IoT system to extract valuable information in real-time for groundwater resource management. Unlike previous surveys which solely focussed on particular groundwater issues related to simulation and optimisation management methods, nonetheless, this paper seeks to highlight the current groundwater management models as well as the IoT contributions.
\end{abstract}

Keywords: Internet of Things (IoTs), groundwater level, groundwater resource; groundwater management models, groundwater monitoring system, wireless sensor network

\section{Introduction}

About approximately one-third of the global freshwater consumption depends on groundwater resources thus, it has become an important source of freshwater globally [1]. It is also one of the most valuable unlimited natural resources in the world. In the water cycle, the freshwater resource is approximately about $4 \%$ of the total water available on earth out of which the remaining $96 \%$ is salty, in the seas and oceans [2]. Meanwhile, only about $0.001 \%$ is available as a groundwater resource that is hidden underground, while $75 \%$ is ice and about $25 \%$ is liquid water [3]. Therefore, groundwater resources constitute 
approximately $98 \%$ of all fresh liquid water available on the earth [4]. Since both plants and animals depend on water, therefore, the interaction between surface water systems and groundwater resources is essential for basic life on the earth. This makes groundwater the largest distributed storage of freshwater which plays an important role in an ecosystem's sustainability as well as in aiding human adaptation to both climatic change and variability [5]. Human beings largely depend on groundwater resources as a major supply of their drinking water. Thus, efficient measurement, monitoring and management of groundwater resources are crucial to ensure its future sustainability. Nonetheless, human activities and lack of planning on these activities have led to groundwater quantity shortage in the aquifer, land subsidence, saltwater intrusion, high cost of water production, overexploitation, unhygienic and quality contamination [6-16]. Also, the management and sustainability of groundwater resources is a global critical issue. This is in line with Goal 6 of the Sustainable Development Goals (SDGs) adopted by the United Nations General Assembly which seeks to achieve a universal reduction in water scarcity, sustainable water management, and to substantially increase the efficiency of water usage by 2030 [17].

In the aquifer, the system of groundwater is slow and dynamic. This is because it responds to variation in hydrological stresses like climate change, land use, abstraction, etc in two ways [45, 214]. The first way is to balance out the recharge and discharge of the aquifer system in a process known as an equilibrium state, thus, allow the aquifer to exist indefinitely, or secondly, when the hydrological stress is so large beyond the equilibrium state, thus, leading to a finite aquifer's life span $[152,215]$. Depending on a region, replenishing a pumped-out groundwater resource is typically low, thus leading to a reduction in the level of resources. In addition to usage, as a result of high non-linear and non-stationary natures of groundwater resources in time series, its efficient management depends on various complex factors such as precipitation, and other environmental factors [18]. Consequently, groundwater models are essential management tools that are used to locate these adverse effects and an ideal balance between groundwater abstraction on the aquifer [216]. Furthermore, groundwater modelling assists in determining an aquifer's response to hydrological conditions as well as sustainable management of groundwater resources [217]. Therefore, groundwater models are crucial to ensure a sustainable future water scarcity reduction, overexploitation, and to improve water efficiency usage. Consequently, it is of vital importance that an effective management model for accurate groundwater level management model be developed [19-20].

Measurement of groundwater level is important to avoid depletion of the groundwater resource as earlier stated [2]. Groundwater level measurement assists in determining the hydrological stress acting in an aquifer and provide data for efficient management. For a long-time forecast, and management, ground water level measurement supplies data to develop a groundwater model [21-22]. Therefore, this has made groundwater management models become a standard instrument used by water managers and professionals to solve most groundwater-related problems. Thus, there are many models such as datadriven models, numerical models as well as nonlinear models that are used for groundwater modelling [58-60]. However, it is important to understand the nature and characteristics of groundwater levels to be able to efficiently measure or model groundwater resources. Additionally, the nature of groundwater level measurement in time series was described to be non-stationary and non-linear which depends on various complex surrounding agents such as precipitation, intervening aquitards, groundwater aquifers, and other hydrogeological characteristics of the aquifers involved [23]. Also, the groundwater aquifers systems' interaction with the surface water at different temporal-spatial scales was described as intrinsic heterogeneous systems that are strained by a knotty hydrogeological state [24-25]. Thus, the processes and the physical attributes that form groundwater flow within an aquifer are very heterogeneous [26]. To effectively take into consideration all these properties of groundwater resources, various groundwater management models warrant complex and highly distributed models in time series. Previously, the tendency in groundwater resources management through distributed modelling was to increase the numerical resolution, include many physical attributes, as well as to enlarge the model's 
domain using either a finite difference approximation or a finite element method [27-30]. Although the application of either the finite element or finite difference methods to groundwater resources management have enabled real-world and complex systems to be modelled, this has led to an increase in the model's running time.

In many instances, groundwater levels are manually measured using a data logger coupled with a pressure transducer, electrical probes or a graduated steel tape dipper [2, 31]. Although these techniques are simple and easy to use, they are prone to human errors, are unreliable, and are inefficient. Since the development of super fast-speed computers as well as user-friendly software, the field of hydrogeology has frequently used physicalbased numerical techniques to model groundwater. However, it is difficult to define the needed information accurately because spatial data on hydrological as well as geological properties of the aquifer are needed [45]. Hence, data gathering is essential to maintain groundwater resources management and to perform crucial water-related functions such as mitigating against drought [31]. Likewise, many researchers have combined many physical numerical techniques such as both simulation and optimization modelling methods to manage groundwater resources [22, 32-38]. Also, different groundwater resource management models have been developed to minimize groundwater resources scarcity [18, 23-25, 39-57].

Chang et al developed a numerical groundwater resource model from a conceptual model but failed to capture the computational complexities nature of the groundwater aquifer system while focusing only on the fundamental as well as the main principles [24]. This is because it is difficult to formulate both groundwater flow equations and prove the hydrogeological parameters for conceptual models due to computation complexity. Additionally, there are uncertainties and difficulties in obtaining long time series data for groundwater levels using numerical modelling processes [23,42,61]. Thus, making long time series models time-consuming, laborious, unscalable, and costly [46]. However, it is important to achieve an acceptable groundwater resources model performance efficiency. But, previous information was not often available because most government agencies in charge of water often collect these data just once or twice a year during the agricultural season [56]. Also, the majority of traditional groundwater models are process-based [45]. This means much supplementary spatial data on the aquifer's hydrological and geological properties is mandatory. Further challenges occur in groundwater modelling due to the complexity of hydrogeology subsurface as well as spatiotemporally variable in societal pumping activities [57].

As identified in most literature, there are many efforts developed previously to profer solutions to groundwater modelling. Over the years, the use of machine learning as an alternative solution for the modelling of groundwater has gained more attraction [24]. In contrast with numerical models, machine learning models are data-driven and requires learning from historical measured data from the aquifer system. These models do not need to comprehend the physical processes or the internal framework of an aquifer [216, 218]. Other solutions such as linear and nonlinear programming techniques which are driven solely by a data acquisition have also been proffered [9,14,15,32,34,37,38,46-48,62]. Datadriven classification models such as Genetic Programming (GP), Artificial Neutral Networks (ANNs), Fuzzy Logic, as well as Support Vector Machines (SVMs), and time-series techniques such as Autoregressive Integrated Moving Average (ARIMA) and Autoregressive Moving Average (ARMA) are proven alternatives to conceptual models $[18,39,42,43]$. However, they are not scalable enough when there is a change in dynamic groundwater level with time as well as when available data is insufficient to give accurate results [45]. Furthermore, Husna et al and Kenda et al observed that the majority of groundwater resource management models have failed to capture computation efficiency and scalability $[44,45]$. Despite the huge improvements in the existing groundwater resource management models, researchers pointed out lack of efficiency and scalability as a result of considerable uncertainty, over-dependent on unavailable additional datasheets and potential substantial errors [63-70]. Although, both data-driven machine learning models and nu- 
merical techniques have been used extensively in modelling groundwater resources, however, the numerical techniques have physical limitations such as aquifer's state as well as extensive physical properties qualification, laborious, and expensive [219]. Therefore, it is necessary to develop a model that can identify these limitations and use the information for groundwater management and policy-making [220].

In 1990, John Romkey created the first world's Internet of Things (IoT) Interop Internet Toaster device, while the term IoT was first conned out in 1999 by Kevin Ashton [221]. This was a toasting machine that was operated from a computer system that was accessing the management information base using a simple network management protocol and the internet protocol [222]. Since then, over 500 million devices have been connected to the internet. Furthermore, about 20 to 30 billion IoT devices are estimated to be connected to the internet by 2021 [223]. Over the years, the concept of the IoT has been embraced in areas including smart water, smart healthcare, smart agriculture, smart climate, and so on [71,72]. This concept of the IoT refers to a phenomenon in which there is a connection of many smart things such, sensors, mobile phones, utility and industrial components through networks and possess data analytics capabilities. Thus, smart sensors and pressure transducers have found their usage in groundwater resource management using the traditional IoT architecture for continuous data acquisition, analyses and processing. In a traditional IoT architecture, the IoT data generated by the smart devices are transmitted into the remote cloud through the internet [73]. As a result of huge data transfer from IoT devices into the cloud, the traditional IoT internet architecture has become inefficient for analysing and processing the collected data [72]. This is because this computation process exerts pressure on the cloud computing linked network, hereby, causing untold stress. Furthermore as identified in most literature, the cloud is not efficient and scalable entirely to sustain IoT big data in real-time due to its communication latency and network bandwidth [71-75].

Furthermore, the use of IoT in the management of groundwater levels as well as in the development of groundwater data-driven models has been instrumental in detecting areas of groundwater resources quantity reduction. However, the sensing instruments deployed into the observation wells have too low resolution and are too indirect to be of use for local regional assessments in geodetic methods $[64,66,69,70]$. Consequently, improvements in IoT technology in combination with improved geophysical modelling and dataassimilation are needed to meet computation efficient and scalable IoT architecture needs for groundwater resources management models.

While previous surveys have solely focussed on particular groundwater issues related to mathematical modelling and simulation models, this current review seeks to provide an IoT based inclusion perspective as it relates to groundwater resources management. Therefore, this paper aims to present a review of existing groundwater resource management models, their limitations and the current challenges as well as IoT (remote sensing and geographic information system) inclusion.

The arrangement of this paper is as follows; section 2 discusses the overview and organisation of groundwater level management models. The groundwater management and IoT are presented in section 3, while section 4 contains the conclusion and thereafter references and acknowledgement.

\section{Overview and Organisation of Groundwater Level Management Models}

This section aims to provide an overview and organisation of the groundwater level management model hierarchy.

\subsection{Sources of Groundwater Recharge to An Aquifer}

Naturally, the source of groundwater aquifer recharge is the rainfall from the climate. Therefore, any upset in the climate condition such as less intensive rainfall can lead to an alteration in the quantity of recharge to an unconfined aquifer [224]. Therefore in a groundwater aquifer system, there is an assumption that the discharge is cancelled by the 
recharge, hence, there is no prolonged period of shortage in storage [152]. Although, before an abstraction occurred, there may be daily occurrences of fluctuations on the groundwater's aquifer system, however, the system remains in a dynamic equilibrium state [152]. Moreover, hydrological stress on the groundwater system is a result of fluctuation between the discharge and recharge due to climatic changes [215]. The quantity of water required to recharge an aquifer is also affected as a result of an evaporation increase [225]. Consequently, the concept of water balance or budget follows the law of conservation of mass, delineates the condition of an aquifer in its natural balance before abstraction over a prolonged duration [215].

After an abstraction has occurred, the groundwater aquifer system can be artificially recharged via a pumped borehole. Therefore, a groundwater aquifer system is balanced by water from either or a combination of three methods. These are; by increasing recharge to the borehole via pumping, by reducing storage in the aquifer and, by decreasing the discharge from the aquifer caused via pumping $[152,226]$. During the artificial pumping of groundwater from a borehole, a capture is created. A capture principal as a result of pumping can be described as a decrease in discharge, as well as an increase in recharge of water that will not voluntarily flow into the groundwater system [227]. Hence, the new equilibrium or water balance will be achieved after enough capture is achieved [228].

\subsection{Overview of Groundwater Management Models}

A groundwater management model is a powerful mathematical aquifer management tool that utilises numerical methods such as linear, quadratic programming and machine learning with a combination of groundwater governing flow and transport equations to solve groundwater management problems [76-84]. Therefore, a traditional simulation model is utilized to answer "what if" related questions while an optimisation model provides a solution to "what is the best" under given limiting boundaries [22]. Over the years, groundwater hydrogeologists have attempted to evaluate groundwater resources using numerical simulation models. The application of numerical simulation models by the researchers in the field of groundwater hydrology has assisted them to increase their understanding of regional aquifers functions about a particular facet of groundwater systems as well as testing the hypotheses [13, 22, 26, 32, 34, 51, 52, 66, 85]. Also, modelling of real and complex groundwater systems have been made possible via the use of finite difference and finite element simulation models. Furthermore, this has enabled the idea for evaluation and conception framework towards effective management of groundwater resources, including impacts of chemical contaminants, surface water interaction, and its withdrawal. In a real-world groundwater resources management scenario, the groundwater management problems are multi-dimensional and hence single objective simulation management methods are not adequate.

Although simulation as a tool is often utilised by groundwater managers, nonetheless, it fails to capture critical functional and physical restrictions while also sideling the management goals. Therefore, the use of the simulation method only will not be able to provide the optimal management objective because determining the proper objective function of a groundwater system is very challenging, and can not be ignored. Consequently, a combination of simulation and optimisation management models is needed. An optimisation-based groundwater management model aims to provide a solution to a specified goal in the best possible manner within the various limiting boundaries. These limiting boundaries emanate from both the physical patterns of the groundwater system and the manager's requirements. In addition, optimisation as a simple tool employs the capabilities of both nonlinear and linear formulations to solve a given complex mathematical problem. Therefore, simulation-optimisation groundwater management models in optimisation formulation merge aquifer simulation models in exchange for constraints. Thus, optimisation and simulation groundwater models have been developed for various utilisation like management of groundwater resource policies, restoration of surface and groundwater resources, control of aquifer flows and aquifer simulation simultaneously [22, 86-90]. 


\subsection{The organisation of groundwater management models}

The groundwater management models can be classified into two main groups. These are the physical classification models and data-driven classification models [56], Furthermore, studies have shown that the combination of optimisation and simulation management techniques which are data-driven models that could be organised into two groups; groundwater hydraulic management models and groundwater policy evaluation and allocation models [22, 23, 85, 87, 91]. Figure 1 shows the organisation of groundwater management models into groups.

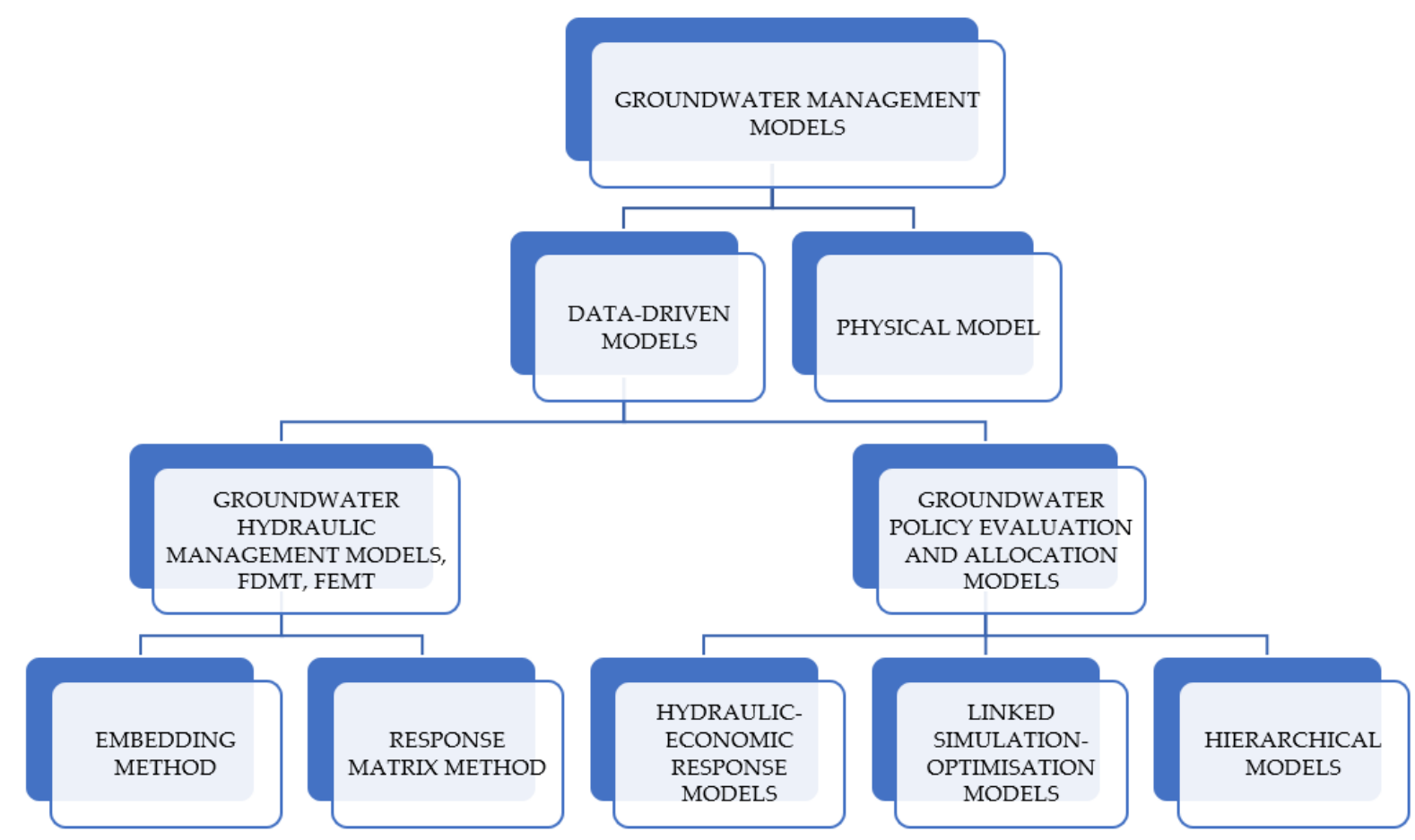

Figure 1. The organisation of groundwater resource management models adapted from [85].

The physical classification models are based on the use of physical parameters of the groundwater bed to determine any changes in the water level. However, these models are difficult to execute, expensive, and need to be partitioned to obtain numerical information [54]. Furthermore, although groundwater management models are essential tools to examine the negative effects of human activities on the dynamic nature of groundwater resources, be as it may, the physical and the hydrogeological surroundings require reliable data $[92,93]$. The aquifer of the physical ground water management models aquifer's surrounding includes the topography, soil, climate, land use, agricultural practise, demand for groundwater usage, drainage and canals ditches. Whereas, the hydrogeological surrounding refer to the groundwater dynamism, the hydraulic parameters for each of the aquifer layers, aquifer system parameters, as well as aquifer boundary conditions. This hydrogeological surrounding varies in time and space $[41,94]$. Above all, to achieve accurate modelling results from a physical model, it is essential to have a calibration of the model using accurate data. Thus, achieving more efficient and accurate computation must be explored deeper.

Data-driven models' groups are differentiated on the objective function where the decision is based solely on groundwater hydraulics functions and the other whose management decision is based on evaluation of policy as well as an allocation of groundwater economy. Thus, the former is aimed at the management of groundwater stresses like rechargings as well as dischargings, well costs, and aquifer hydraulics. These groundwater hydraulic management models groups treat both the hydraulic heads and stresses as direct management objective function decision variables. On the other hand, the groundwa- 
ter policy evaluation and allocation models group are aimed to solve groundwater management problems by examining the complex relationship between groundwater as well as surface water and their economic interactions. These evaluations form the base of regional groundwater policy [64, 86, 87]. The data-driven groundwater model in its primitive structure possess four basic components: it is nonlinear concerning its decision variables; requires the solution of nonlinear partial differential equations to describe the transport as well as the flow of groundwater; it is stochastic as its primary uncertain source is associated with the aquifer simulation mode, and; it is a mixed-integer programming decision because it contains discrete and continuous objective functions [14, 95]. Therefore, generally, these models are identified by their multiple objectives optimisation characteristics and possess robust economic management units.

In all these groups of optimisation and simulation groundwater management models, a set of different differential mathematical equations are used to describe the groundwater flow. Thus, a mathematical model is formed as a result of the combination of these different differential equations with their boundaries as well as initial conditions. The basis of groundwater modelling is governed by the combination of Darcy's law and conservation of mass law through an anisotropic nonhomogeneous porous medium [96-98]. The combine flow equation is represented by equation (1);

$$
\frac{\partial}{\partial \mathrm{x}}\left(\mathrm{T}_{\mathrm{x}} \frac{\partial \mathrm{h}}{\partial \mathrm{x}}\right)+\frac{\partial}{\partial \mathrm{y}}\left(\mathrm{T}_{\mathrm{y}} \frac{\partial \mathrm{h}}{\partial \mathrm{y}}\right)+\mathrm{W}=\mathrm{S} \frac{\partial \mathrm{h}}{\partial \mathrm{x}}
$$

where $h$ is the hydraulic potential (L), $x$, and $y$ are cartesian coordinates $(\mathrm{L}), T_{x}$ and $T_{y}$ are the components of the transmissivity tensor $\left(\mathrm{L}^{2} \mathrm{~T}^{-1}\right), \mathrm{W}$ is a general source/sink term $\left(\mathrm{LT}^{-1}\right)$, while $S$ is the storage coefficient, and $t$ is time $(\mathrm{T})$. The efficient measurement of groundwater level (head) is important to improve the model usage. Hence, various non-linear time-series mathematical models have been proposed to measure groundwater levels in one as well as two-dimensional flow. However, many physical management model parameters should be treated in three dimensions. This three-dimensional management application method is an open method for groundwater resources management.

\subsection{Data-Driven Classification Models}

The latest machine learning data-driven classification models such as Artificial Neural Network (ANN) technique, Genetic programming (GP), Adaptive Neuro-Fuzzy Inference System (ANFIS), and support vector machine (SVM) as well as time series methods such as Autoregressive Integrated Moving Average (ARIMA), Multiobjective Function Approach, and Autoregressive Moving Average (ARMA) are proven alternatives to physical models. They are treated as nonlinear standard estimators that can overcome difficulties associated with physical models and are less costly. However, they are less accurate with insufficient data availability and when the focus of research is not based on a physical mechanism [43]. Furthermore, there are numerical groundwater models developed from a conceptual model. However, these models often neglect the complexities while focusing only on the main fundamental principles of the groundwater systems [24]. Meanwhile, finding long time-series data for a numerical model is exceedingly challenging during the modelling processes.

\subsection{Data-Driven Mathematical Models for Groundwater Resources Management}

The groundwater resources prediction model is described as a regression problem $[45,99,100]$. This means the goal is to forecast, predict and manage any changes in the groundwater resources on any particular day according to the available data. Thus, datadriven mathematical models use previous data based on the underlying process behind particular phenomena to learn the best forecast result. Thus, the goal of this section is to provide insight into the mathematically formulated for managements of groundwater resource.

\subsubsection{Sequential Gradient Restoration Algorithm (SGRA) Model}


The Sequential Gradient Restoration Algorithm (SGRA) is a dual-phase path to solve non-linear programming (NLP) problems. Beginning from a feasible design point of view, the gradient phase decreases the value of the objective function while at the same time fulfilling the obligation of the linearized active constraints. This will lead to constraints violation of the nonlinear active constraints. Consequently, the restoration phase catalyses the design to feasibility which may produce a new as well as a distinct set of constraints. This process of two phases cycle is repeated until the optimum is achieved [101]. This technique incorporates a decent property with each cycle. The SGRA uses an active constraint strategy just like other algorithms. This method has been favourably compared to the generalized reduced gradient (GRG) and the gradient projection method. However, in comparison, the SGRA combines the two phases [101, 102].

The SGRA assumes the inequality constraints of the form by equation (2);

$$
g_{j}(X) \geq 0 ; j=1,2, \ldots, m
$$

The general problem is defined as

Minimize

$$
f(X),[X]_{n}
$$

Subject to:

$$
\begin{gathered}
{[h(X)]_{t}=0} \\
{[g(X)]_{m} \leq 0} \\
X^{\text {low }} \leq X \leq X^{\text {up }}
\end{gathered}
$$

Only active inequality constraints are of interest in the SGRA. Although equality constraints are always active. Active inequality constraints also include violated constraints. If ' $v$ ' indicates the set of active constraints, equation (4) and equation (5) can be combined into a vector of active constraints $(\Phi)$;

$$
\Phi(X)=\left[\begin{array}{c}
h(X) \\
g(X) \geq 0
\end{array}\right]_{v}
$$

The number of active inequality is v-l. The Lagrangian for the problem can be expressed in terms of the active constraints alone (since the multipliers for the $g_{f}(X)<0$ will be set to zero as part of KT conditions]. The KT conditions are then expressed by equations 8 a to $8 \mathrm{c}$.

$$
\begin{gathered}
\nabla_{X} F\left(X, \lambda^{v}\right)=\nabla_{x} f(X)+\left[\nabla_{X} \Phi\right] \lambda^{v} \\
\Phi(X)=0 \\
\lambda_{v-t} \geq 0
\end{gathered}
$$

where $\left[\nabla_{x} \Phi\right]=\left[\begin{array}{llll}\nabla_{x} \Phi_{1} & \nabla_{x} \Phi_{2} \ldots \nabla_{x} \Phi_{v}\end{array}\right] ; \quad \lambda^{v}=\left[\begin{array}{lll}\lambda_{1} & \lambda_{2} \ldots & \lambda_{v}\end{array}\right]^{\mathrm{T}}$

Gradient phase: Given a feasible design $X^{i}$, the neighbouring gradient point can be expressed as

$$
\tilde{X}_{g}=X^{i}+\Delta X
$$

where $\delta \mathrm{f}<0$ and $\delta \Phi=0$. By imposing a quadratic constraint on the displacement $\Delta \mathrm{K}$ in equation (9), the problem can be set up as an optimization subproblem whose KT conditions are determined as given in equation (10)

$$
\Delta X=-a \nabla F_{x}\left(X^{i}, \lambda^{v}\right)=a S
$$

In this model, the search direction is directly proportioning to the gradient of the Lagrangian, which is an improved and model feature. To solve the Lagrangian, the Lagrange multipliers must be computed. This is solved by solving a system of $v$ linear equations given in equation (11);

$$
\left[\nabla_{X} \Phi\left(X^{\mathrm{i}}\right)\right]^{\mathrm{T}} \nabla_{X} f\left(X^{i}\right)+\left[\nabla_{X} \Phi\left(X^{\mathrm{i}}\right)\right]^{\mathrm{T}}\left[\nabla_{X} \Phi\left(X^{i}\right)\right] \lambda^{v}=0
$$


Stepsize for gradient phase: The stepsize calculation is based on driving the optimality conditions in (8a) to zero. Therefore, if the

$$
\tilde{X}_{g}=X^{i}-\alpha \nabla F_{X}\left(X^{i}, \lambda^{v}\right) \nabla_{X} F\left(X, \lambda^{v}\right)=\nabla_{x} f(X)+\left[\nabla_{X} \Phi\right] \lambda^{v}
$$

thus, the optimum $\alpha^{\wedge *}$ is solved by cubic interpolation while trying to satisfy the condition in (13)

$$
\nabla_{X} F\left(\tilde{X}_{g}, \lambda^{v}\right)^{T} \nabla_{X} F\left(X^{i}, \lambda^{v}\right)=0
$$

However, an adequate step must be taken that this stepsize does not cause significant constraint violation. This is can be ensured by capping the squared error in the constraints by a suitable upper bound which is set up as

$$
\Phi\left(\tilde{X}_{g}\right)^{T} \Phi \tilde{X}_{g} \leq P_{\max }
$$

Furthermore, the Pmax is related to another performance index $Q$, which is the error in the optimality conditions [82]. Thus,

$$
Q=\nabla F_{X}\left(\tilde{X}_{g}, \lambda^{v}\right)^{T} \nabla F_{X}\left(X^{i}, \lambda^{v}\right)
$$

Restoration Phase: After the end of the gradient phase, it is assumed the function will have decreased but there would be some infeasible constraints (supposing at the initial stage of the gradient phase, there were at least more than one nonlinear active constraint). In the restoration phase, a feasible solution within the neighbour would be established. This is achieved by making sure that the linearized constraints are feasible. However, before this, the active constraint set has to be updated (v) since the initial feasible constraints could have become infeasible (and previously infeasible constraints could have become feasible) as a result of the change in design caused by the gradient phase. Thus, the design vector and the changes in design for this restoration phase can be written as

$$
\tilde{X}_{r}=\tilde{X}_{g}+\Delta \tilde{X}_{r}
$$

The change in design for this restoration phase $\Delta \mathrm{X}_{-}^{\sim} \mathrm{r}$ can be obtained as a least square error in the design changes subject to the satisfaction of the linear constraints. Thus, equation (17) is used to calculate this change in the design using NLP

$$
\Delta \tilde{X}_{r}=-\nabla_{X} \Phi\left(\tilde{X}_{g}\right) \sigma^{-v}
$$

where $\sigma^{\wedge}(-\mathrm{v})$ is the $\mathrm{V}^{-}$vector Lagrange multiplier of the quadrantic subproblem. Furthermore, the values for the multipliers are established through the linear equation in equation (18)

$$
\mu \Phi\left(\tilde{X}_{g}\right)-\nabla_{X} \Phi\left(\tilde{X}_{g}\right)^{T} \nabla_{X} \Phi\left(\tilde{X}_{g}\right) \sigma^{-v}=0
$$

where factor $\mu$ is a user-controlled parameter to discourage large design changes. The Restoration phase is iteratively applied until equation (19) is feasible

$$
\Phi\left(\tilde{X}_{r}\right)^{T} \Phi\left(\tilde{X}_{r}\right) \leq \varepsilon_{1}
$$

where $\varepsilon_{-} 1$ represent a small number.

After the restoration phase, the constraints are feasible and the next cycle of the Gradient-Restoration phase can be applied again.

\subsubsection{Linear Regression}

Linear Regression (LR) is one of the oldest and most widely used groundwater management models. Therefore, LR can be defined by equation $(20)[103,104]$.

$$
y=X \beta+\varepsilon,
$$

where $y$ is the vector of the groundwater level changes values from the observation well, $\mathrm{X}$ is the aquifer's independent parameters such as the historic weather data, in a two rows matrix, $\beta$ is the parameter of forecasting vector that is under the investigation, while $\varepsilon$ is 
the errors' vector. In LR, the goal of applying this model technique is to minimise the validation set errors as well as to learn the vector parameter $\beta$. Many parameter estimation model techniques are available, however, the least-squares estimation techniques are most popular [45].

\subsubsection{Regression Tree and Gradient Boosting}

Decision making is an important aspect of the linear regression groundwater management model [105-107]. Therefore, decision trees based algorithm known as Regression Trees (RTs) was developed. RTs operate by diving each ground water resource value into smaller subspaces that are represented by a tree leaf. Thus, the learning samples are obtainable by averaging all the samples as well as by introducing another LR model at the node. The accuracy of this model is a function of introduction ensembles of regression. In environmental data-driven modelling applications, the RTs algorithm is very important as it is easy, fast, and successfully deployed. Gradient Boosting (GB) is the most used method in various fields. This is because the GB make practical and effective use of ensemble weaker trees from the learning set to provide final predictable results, nonetheless, it stacks them additively [108-109]. Thus, the loss function differentials are approximated in each succeeding stage. Equation (21) is an example of a loss function

$$
L\left(y, F_{m}(x)\right)=\frac{1}{2}\left(y-F_{m}(x)\right)^{2}
$$

From (21), the true value is represented by y. $F_{m}(x)$ is the model's prediction after the $\mathrm{m}$-th stage. As stated earlier, The RTs model prediction $F_{m}(x)$ combines all the weaker tree's results.

\subsubsection{Artificial Neural Network (ANN) Model}

An artificial neural network (ANN) is a black box tool with a resemblance of a human brain's biological neural networks in certain performance characteristics which consist of an enormous equidistant distribution processing system [19, 110, 111]. However, Feedforward neural networks (FFNN) models are the most commonly used and employed in modelling [23, 112, 113]. A normal ANN model is made up of a three-layer FFNN model of an input layer, hidden layer, and output layer as well as artificial neurons with each layer interwoven with those in the next layer known as Multilayer Perception Network (MLPN). As such, the output of a node layer determined the weight, as well as the type of transform of the sole function of the input it received from the former layer. Therefore, previous research trained the ANN with the Bayesian regularization algorithm and tansigmoid transfer function [23,39,43,45]. This is mathematically expressed by equation (22).

$$
y_{j}=f\left(\sum_{i=1}^{N} w_{j i} x_{i}+b_{j}\right)
$$

where the input vector is $x_{i}$, the output is $y_{j}$, the bias is $b_{i}$, the weight connecting $x_{i}$ and $x_{i}$ is $x_{j i}$ the number of nodes is represented by $\mathrm{N}$, while the activation function is $\mathrm{f}$ within the presentation layer. The application of ANN by many researchers has proved to be a success. The ANN time series data trained model was used successfully to predict the principal factors affecting algal blooms in a man-made Lake Juam reservoir [114]. Furthermore, ANN models have been applied in various scenarios such as estimation of regional index flood, in an ungauged catchment of the Chindwin River in Myanmar, to evaluate an extreme daily precipitation's potential in Athens, Greece, for river flow rate and sediment load from Rantau Panjang Station on Johor River [115-118]. The results showed that ANN models are superior to the conventional regression method.

\subsubsection{Adaptive Neuro-Fuzzy Inference System (ANFIS) Model}

An adaptive neuro-fuzzy inference system (ANFIS) model can be described as an adaptive neural hybrid algorithm that is based on a fuzzy inference system. This model 
was first inaugurated in 1993 by Jang et al [119, 120]. Furthermore, ANFIS has been found to be capable of approximating any continuous and real function in a compact set to an acceptable degree of accuracy universally. In the ANFIS model, it is assumed that the fuzzy inference system has two inputs $x$ and $y$ as well as one output $f$. Thus, it can be expressed by the set of rules in equations (23) and equation (24).

$$
\begin{aligned}
& \text { Rule 1: If } x \text { is } A_{1} \text { and } y \text { is } B_{1} \text {; then } f_{1}=p_{1} x+q_{1} y+r_{1} \\
& \text { Rule 2: If } x \text { is } A_{2} \text { and } y \text { is } B_{2} \text {; then } f_{2}=p_{2} x+q_{2} y+r_{2}
\end{aligned}
$$

where $\mathrm{x}$ and $\mathrm{y}$ are the crisp inputs to the node $i$, the low, medium or high characterized linguistic labels by the convenient membership functions are represented by $A_{i}$ and $B_{i}$. Parameters of the first-order fuzzy model are represented by $p_{i}, q_{i}$, and $r_{i}(i=1,2)$. The ANFIS models have a higher capability for modelling non-linear dynamic hydrology and diverse water resources among all the models, for effective water management. In terms of efficiency and accuracy, the ANFIS was utilised with machine learning for estimation of pan evaporation daily as well as long-term dam inflow water [121-123]. The result showed that the ANFIS model performed better than any traditional empirical techniques. The ANFIS model has been used for rainfall-runoff modelling, groundwater modelling as well as evaporation modelling [23, 124-126].

\subsubsection{Support Vector Machine (SVM) Model}

The support vector machine (SVM) is a machine learning approach characterized by the statistical learning principle [127-128]. Therefore, its solution is obtainable via an optimization algorithm using a regression hyperplane. Although, in a regression SVM model, an insensitivity loss function, as well as a regression hyperplane, is a convex dual optimization problem. In addition, the Sequential Minimal Optimisation (SMO) algorithm is often used to provide a solution to problems involving dual optimisation of the SVM. Mathematically, the SVM deterministic function is expressed as shown in equation (25).

$$
f(x)=w \cdot \phi(x)+b
$$

where $w_{i}$ is a weight vector, while $\mathrm{b}$ is a bias, the high-dimensional feature space $\mathrm{x}$ is mapped by a non-linear transfer function $\phi$. This SVM model has been deployed by many researchers in the field of engineering to solve hydrogeology and hydrology drawbacks. The results showed that the SVM model performed better than the ANN model. Limited climatic data were used to evaluate daily evapotranspiration using the SVM model in an extremely arid region [129]. Of the four models used, the SVM model proved to be the best. Also, the SVM model assembled with quantum behaved particles warm optimisation SVM-QPSO model was used to forecast streamflow every month [130]. The result showed that the SVM model ensures a high prediction degree of streamflow reliability and accuracy. In addition, several researchers applied the SVM model to predict, estimate, and evaluate the streamflow as well as, water level of Lake Van in Turkey [61, 131-133]. The results showed that the SVM model outperformed the regression and ANN models.

\subsubsection{Empirical Mode Decomposition (EMD)}

Empirical mode decomposition (EMD) is a data-adaptive full algorithm technique used for analysing signals that are non-linear as well as non-stationary [134]. Thus, for EMD to perform its basic function of decomposing an original signal to a various number of intrinsic mode functions (IMFs), two conditions must be met: (a) number of extrema and zero crossings must be equal or differ at most by one, and ; (b) functions are symmetric and the mean value of the upper, as well as lower envelopes, should be zero. However, mode mixing has been identified as the major shortcoming of EMD implementation [135]. Mathematically, the EMD can be obtained using equation (26).

$$
x[x]=\sum_{k=1}^{K} I M F_{k}[n]+R[n]
$$


where the corresponding residue to the signal approximation at the lowest resolution is represented by $R[n]=m_{K}[n]$ and $I M F_{k}[n]$ is the k-th IMF. It is however widely claimed that the EMD, as well as the Ensemble EMD (EEMD), are computationally intensive to run. Over the past years, both the EMD and EEMD have demonstrated higher effectiveness in comparison to the Fourier techniques. Thus, it has been extensively deployed in various disciplines such as image analysis, the health sector for diagnosis, biomedicine and big data logging.

Table 1 shows a summary of the latest data-driven groundwater resources management methods of modelling.

Table 1. Summary of data-driven groundwater resource management modelling methods.

\begin{tabular}{|c|c|c|}
\hline Authors & Methods & Objectives \\
\hline Valipour et al $[55,136]$ & $\begin{array}{l}\text { Improved Random Forest Regression With } \\
\text { A Combination Of Random Features }\end{array}$ & $\begin{array}{l}\text { These authors provide the appli } \\
\text { cation of simulation modelling } \\
\text { methods in groundwater re- } \\
\text { source management. }\end{array}$ \\
\hline
\end{tabular}

\begin{tabular}{ccc}
\hline Xuanhui et al $[48,56]$ & $\begin{array}{c}\text { Canonical correlation forest algorithm with } \\
\text { a combination of the random features sim- } \\
\text { ulation model and neuro-particle swarm } \\
\text { optimisation and neuro-differential evolu- } \\
\text { tion methods }\end{array}$ & $\begin{array}{c}\text { These authors proposed this } \\
\text { method to solve the problem of } \\
\text { datarcity on a site and low-di- } \\
\text { mensional data }\end{array}$ \\
\hline $\begin{array}{c}\text { Emamolizadeh et al } \\
{[39-44,53]}\end{array}$ & Artificial Neural Network (ANN) based & $\begin{array}{c}\text { The objective of this method was } \\
\text { to provide accurate predictions } \\
\text { without an increase in costly } \\
\text { computational time. }\end{array}$ \\
\hline
\end{tabular}

The effectiveness of these methods and solutions could not be estab-

lished by these authors with a field experiment. This is due to costs and time constraints, increase in computational complexity as well as needs partitioning

The accuracy of this method is instantaneous. Hence, this makes it unsuitable for groundwater resource prediction over a long period.

ANN models are prone to incur the problems of local minima and overfitting.

Although SVM is robust for
groundwater resource prediction
as highlighted by these authors, it

Yoon et al $[46,53,56,61$, $137,138]$

Super Vector Machine Method (SVM)

Mustafa et al [22, 49, 50, Groundwater flow model and multiobjec- to evaluate the effects of human $53,57,139]$ tive method
The objective of this model was

activities on groundwater dynamics

The objective of this model is to overcome challenges with both ANN and SVM models

The objective of this method is to is sensitive to redundant and outovercome the variation in lier data. Also, it is not scalable groundwater level prediction enough and requires more time because of trials and errors. SVM also has high parametrization complexity.

This model is negatively hampered due to a lack of data in arid and semi-arid regions. Furthermore, this model requires a good quality of evidence-based data for it to be reliable

Although ANFIS has performance acceptability in modelling many environmental and hydrological phenomena, it has many weaknesses such as probable entrapment at local minima and slow convergence makes it ineffective in modelling.

With the advancement in data mining for modelling, optimisation, and simulation techniques for groundwater resources management, the use of finite difference and finite element have increased exponentially. Although the use of the Finite Element Modelling Technique (FEMT) was first instigated by Lee and Cheng in 1974, for seawater encroachment in a coastal aquifer [140]. Likewise, Tyson and Weber, in 1963 advocated the use of electronic computers in the simulation of the dynamic behaviour of groundwater basins using the Finite-Difference Model Technique (FDMT) [141]. Consequently, both the FEMT 
and FDMT have been used extensively for the Groundwater Flow Model (GWFM), Hydro-Economic Model (HEM), Calibration (C), Sensitivity Analysis, (SA), Water Balance Model (WBM), as well as Validation/Verification (V) [89]. However, the efficacy of these modelling solutions depends largely on their adequate verification. Table 2 is a summary of some of the relevant researchers that have applied these two modelling techniques in groundwater resources management [89].

Table 2. Summary of relevant application of FEMT and FDMT and their purposes.

\begin{tabular}{|c|c|c|c|}
\hline Study & Application & Modelling Technique & Scheme \\
\hline [142-145] & $\begin{array}{ll} & \text { GWFM } \\
\bullet & \text { SWAP } \\
\bullet & \text { WOFOST } \\
\bullet & \text { SEBAL } \\
\bullet & \text { SLURP } \\
- & \text { SWAP-SWATRE } \\
\text { - } & \text { SIMGRO }\end{array}$ & - $\quad$ FEMT & $\begin{array}{ll}\text { - } & \text { Calibration } \\
\text { - } & \text { Validation/Verification } \\
& \text { Simulation }\end{array}$ \\
\hline$[146,147]$ & $\begin{array}{ll}\bullet & \text { MODFLOW } \\
\bullet & \text { GFLOW } \\
\bullet & \text { MODPATH } \\
\end{array}$ & - $\quad$ FDMT & $\begin{array}{ll}\text { - } & \text { Calibration } \\
\text { - } & \text { Simulation } \\
\end{array}$ \\
\hline [148-152] & $\begin{array}{ll}\text { - } & \text { HYDRUS-1D } \\
\text { - } & \text { SWMS-2D } \\
\text { - } & \text { PLASM } \\
\text { - } & \text { MODFLOW } \\
\text { - } & \text { AQUIFEMM-1 } \\
\text { - } & \text { ISOQUAD } \\
\text { - } & \text { SVAT } \\
\text { SIMGRO }\end{array}$ & $\begin{array}{ll}- & \text { FEMT } \\
- & \text { FDMT }\end{array}$ & $\begin{array}{ll}\text { - } & \text { Calibration } \\
\text { - } & \text { Validation/Verification } \\
& \text { Simulation }\end{array}$ \\
\hline [153] & • $\quad$ SGMP & - $\quad$ FDMT & $\begin{array}{ll}\text { - } & \text { Calibration } \\
\text { - } & \text { Simulation } \\
\text { - } & \text { Sensitivity Analysis } \\
\end{array}$ \\
\hline$[149,150,154-164]$ & $\begin{array}{ll} & \text { MODFLOW } \\
\bullet & \text { SVAT } \\
\text { - } & \text { SIMGRO } \\
\text { - } & \text { SEAWAT } \\
\text { - } & \text { UCODE } \\
\text { - } & \text { ISOQUAD } \\
\text { - } & \text { MT-3D } \\
\text { - } & \text { UPFLOW } \\
\text { - } & \text { HEM } \\
\text { - } & \text { MBM } \\
\text { - } & \text { MLA } \\
\end{array}$ & - $\quad$ FDMT & $\begin{array}{ll}\text { - } & \text { Calibration } \\
\text { - } & \text { Simulation } \\
\text { - } & \text { Validation/Verification }\end{array}$ \\
\hline
\end{tabular}




\section{Groundwater Management and IoT}

This section aims to highlight the relationship and importance of the Internet of Things which comprises Remote Sensing (RS), and Geographic Information Systems (GIS), as it relates to the measurement, monitoring, management, forecasting, and modelling of groundwater resources.

\subsection{Introduction}

Effective groundwater resource management, as well as modelling, is a function of the availability of good quality data pertaining to the information of the observation well. This is because the groundwater resource measurements are the most basis supporting existence for evaluating the information of the quantity of groundwater resources stored within the aquifer [21]. The information about the aquifer's properties may include and is not limited to changes in groundwater level, storage, flow rate, recharge as well as discharge rates. But these data are not collected automatically. Furthermore, Calderwood et al stated that the negative impact of overexploitation, as well as reduction in recharge of groundwater resources, are often unknown, even after years have passed, due to data limitations [31]. In addition, groundwater resources information is strenuous to collect and use due to lack of proper integration between the equipment deployed, irrelevant and inconsistent data as a result of lack of stationary large-scale flow rate hindrances, un-automated groundwater analysis process, and lack of interoperability in the previous systems [[165-170]. Consequently, these limitations are causing untold strains in groundwater resources management. Additionally, most groundwater resources management models can not provide any reliable decision or support without the required data input. Hence, there is a need for a contemporary, scalable, and real-time IoT-based management system solution for groundwater resources management. Therefore, via the advancement recorded in the field of Information and Communication Technologies (ICT), there are many opportunities available to manage groundwater resource crises.

There are various groundwater level monitoring systems. These systems vary in technology, monitoring and management tasks, scalability, the solution they render, and the cost implications. Historically, the traditional technique of measuring groundwater levels involves the use of a manual tape rule. Furthermore, there are emerging threats that the majority of groundwater level measuring networks are been regularly abandoned due to a decline in global groundwater monitoring [171-172]. Consequently, groundwater resources are inadequately monitored often, despite the fact that they are needed for calibration and validation of groundwater resources models [173-174]. These aforementioned challenges can be solved through the use of the Internet of Things (IoTs) techniques [165].

The application and deployment of low-cost IoTs-enabled Wireless Sensors Networks (WSN) technologies in surface water management have gained tremendous progress. However, the contrary is the case in groundwater level management [235]. Although there are few application cases, however, they are synonymous with the use of high power and cost networks, most deployed commercial pressure transducers without outlining their energy implication, power consumption analysis, or the overall cost implication [234]. Consequently, the use of the Internet of Things based Low-Cost Wireless Sensors Networks (LCSNs) has emerged as an alternative to solve these challenges. Contrarily, according to Mao et al and Chan et al, the growing deployment of LCSNs in groundwater resources management has produced a limited quantity of studies with corresponding open data as well as failed to provide much-needed information to the water managers, scientists, and other policymakers [236-238]. Rather, non-technical issues like socioeconomic contexts, operational and financial mechanisms, and stakeholder engagements, which are hindering the advantages of deploying these LCSNs, are mostly concentrated on [237]. Therefore, there is an urgent need to have a better understanding of these emerging challenges, more research papers, development of scientific tools as well as possible available future opportunities in deployments of IoT- based technologies for groundwater resource management. 


\subsection{IoT and Groundwater Level Measurement Techniques}

In recent years, the internet has changed the way human lives. Therefore, the Internet of Things (IoT) as a facet of the internet has become the ultimate layer on which several things such as smart gadgets are interconnected. This concept of the IoT has been embraced in many areas of human endeavours including smart water and groundwater level management. Thus, IoTs techniques are used to collect, transfer, and analysis the required groundwater level data. The major advantage of IoT deployment is its ability to be able to combine with several technologies such as wireless sensors, cloud computing, ubiquitous computing, RFIP, and software [175]. Thus, the groundwater level data management in an IoT environment involves the combination of smart technologies such as sensors to collect data, over a network area, with a combination of software IDE into the cloud server.

Remote sensing (RS) is an example of a classical way of obtaining the much needed hydrological data for ground water level measurements using the internet [176]. However, this can only provide point data. Thus, the challenge remains on how to navigate from point data alone to regionally distributed data. Although the RS can be used to obtain certain groundwater resources parameters, these parameters are not often useful for groundwater management modelling. Consequently, another model will be required to manipulate the acquired data into usable or verifiable data as an input in spatially distributed models [177]. Furthermore, the data acquired via the RS are prone to noise. The substantial and most relevant data for groundwater resource management modelling are the recharge and discharge information. Of these two, recharge is very crucial for the sustainability of groundwater level management. Application of RS for groundwater level modelling was carried out by Dams et al, for mapping out impervious surface changes for hydrological modelling [178]. More researchers also applied the RS technique for the management of groundwater resources [176, 179-181]. To solve these challenges, the IoTs and machine learning techniques can be employed. Apart from RS, groundwater level managements are using situ networks in many aquifer systems around the world. But the difference in each monitoring well depends on the technology used as well as the frequency of the measuring data [182-184]. The situ technique assists in the management of groundwater level by estimating the changes in (groundwater) storage, providing the user's information, flow model calibration, and general up to date system information [184-186].

The IoTs and machine learning techniques involve the acquisition, processing, transfer and analysis of groundwater level data interconnected using intelligent nodes. This combined with the evolution of web techniques has been used in many works of literature. The application of IoTs for monitoring the groundwater level daily variations and safety quality in the mining environment was carried out by Reddy et al, using sensor technologies [187]. Also, Neyens et al monitored groundwater quality and quantity from a desktop using the IoTs-enabled Environmental data Management Interface (EMI) technique [188]. This same technique was also applied to saltwater intrusion monitoring. A low cost IoTbased real-time groundwater resource management system was built for monitoring a community-based network consisting of eleven wells sited in Nova Scotia, Canada [189]. Also, an automated low-cost sensor network for monitoring groundwater levels was designed at the South American Subbasin Groundwater Observatory (GWO), in a real-time scenario [31]. Botta et al presented the IoTs based sensor network review for both quality and quantity measurement of water in a smart city [190]. It should be noted that with big groundwater level data collected from many deployed sensors, there is a new challenge of how to process, store and deal with them. This is an open research bottleneck that needs to be unravelled.

Starting from the evolution of the web technique in the year 1993, several database managers have started to develop web-based Geographic Information Systems (WebGIS) to store the collected real-time and fast data streams [191-192]. The GIS as an example of Database Management Systems (DBMS) is embedded with the topography, geology, geometry, as well as coordinates data to assist in storage, explanation, location, and manipulation of input as well as the corresponding output data information [193]. Therefore, the WebGIS technique performs better in terms of user' quality of service (QoS), can be used 
by multiple users, cost reduction, global reach, as well as cross-platform compatibility [194].

There has been exponential growth in the development of groundwater level measurement IoT based management techniques with a combination of relevant WebGIS. The GIS software known as ARCVIEW and the groundwater model (MODFLOW) were combined for numerical modelling of groundwater resources by Chenini and Mammou [195]. This combination was used in the central region of Tunisia. Similarly, the Managed Aquifer Recharge (MAR) and International Groundwater Resources Assessment Centre's Global Groundwater Information Service (IGRAC's GGIS) combination was successfully implemented using enhanced historical data from approximately 1200 site studies in about 62 nations [196]. The results showed an increase in groundwater resource storage, good recharging levels, and improved water distribution management. In Table 3, a few other existing groundwater level IoT-based management techniques are presented. Most of the highlighted studies combined both web browser and GIS software, and support multiple users as well as tasks.

Table 3. Summary of relevant existing groundwater level WebGIS technique.

\begin{tabular}{|c|c|c|c|}
\hline Technique & Numerical Model & Spatial Interpolation & Limitation \\
\hline $\begin{array}{c}\text { Cloud-based MODFLOW } \\
\text { ArcGIS [197-198] }\end{array}$ & None & Several methods & $\begin{array}{l}\text { This is based on the simulation } \\
\text { modules only. This limitation } \\
\text { does not permit extensive inter- } \\
\text { polation due to the lack of a nu- } \\
\text { merical model }\end{array}$ \\
\hline $\begin{array}{c}\text { Collaborative Geographic Infor- } \\
\text { mation Systems (CGIS) ([165, } \\
199]\end{array}$ & Multi hydraulic & Several methods & $\begin{array}{l}\text { It is based on the computer's } \\
\text { Random Access Memory (RAM) } \\
\text { size. This causes delays or freez- } \\
\text { ing up during processing }\end{array}$ \\
\hline Delft-FEWS [200, 201] & Multi hydraulic & Several methods & $\begin{array}{l}\text { It is based on the computer's } \\
\text { Random Access Memory (RAM) } \\
\text { size. As a result of this limita- } \\
\text { tion, the model experiences low } \\
\text { computation memory during } \\
\text { operation }\end{array}$ \\
\hline $\begin{array}{l}\text { FREEWAT was developed as a } \\
\text { plugging GIS desktop software } \\
\text { QGIS (QGIS Development Team } \\
\text { 2017) [202-204] }\end{array}$ & Multi hydraulic & QGIS & $\begin{array}{l}\text { The interpolation speed is based } \\
\text { on the computer's RAM. This } \\
\text { causes a delay in operation }\end{array}$ \\
\hline HydroShare [205-206] & $\begin{array}{c}\text { It is based on the user's devel- } \\
\text { oped numerical model }\end{array}$ & Based on the user's upload & $\begin{array}{c}\text { It is based on the developed } \\
\text { model and lack space and speed. }\end{array}$ \\
\hline Tethy [207] & $\begin{array}{l}\text { It is based on multi hydraulic } \\
\text { models }\end{array}$ & Several methods & Based on a developed model \\
\hline MAGNET [208] & $\begin{array}{l}\text { It is based on multi hydraulic } \\
\text { models }\end{array}$ & Several methods & $\begin{array}{l}\text { It is limited to a } 10000 \text { mesh } \\
\text { number. Above this number is } \\
\text { not possible. }\end{array}$ \\
\hline
\end{tabular}

\subsubsection{Overview of Groundwater Level IoTs Based System}

Generally, the groundwater level IoTs-based system architecture can be subdivided into three layers. These are the physical layers, the service layer as well as the presentation layer [209]. In the physical layer, the communication equipment, as well as various sensor nodes for basic data acquisition of relevant groundwater level and aquifer information, are built-in. The raw data measured and collected are deployed to the service layer. At the service layer, there are various tools for data analytics. This layer also stores the received data from the physical layer. Both the application and business logic implementation are implemented at this layer, thus making it an important part of the architecture. The presentation layer is the visualisation layer where the users are allowed to interact as well as view the displayed information on a screen monitor. 
Figure 2 shows the overview working representation of the workflow of groundwater level IoTs based monitoring system. This shows the interconnection of the sensors deployed into the well, the nodes, gateway and the end-user platform. The arrows indicate the direction of the flow of data. The solid line represents the direction of the data received, while the broken lines represent the request sent for data. In this system, the IoTs is combined with the GIS to ensure the real-time uploading of groundwater level data, improve the quality of the database, and provide geographical information about the system. The sensors deployed into the observation wells acquire and send the corresponding measurement of groundwater level parameters to their nodes over the Modbus protocol employed. From the nodes, the data is sent via the Long Range (LoRa) wireless network to the gateway. The data is saved into the Message Queuing Telemetry Transport server (MQTT) platform, which is connected to the No relational Structured Query Language (NoSQL) database or any other Graphics Processing Unit (GPU) platform for real-time display. Examples of these web-based clients GPU are ArcGIS, API, Google Map API, ThingSpeak and WebGL [199, 210-213].

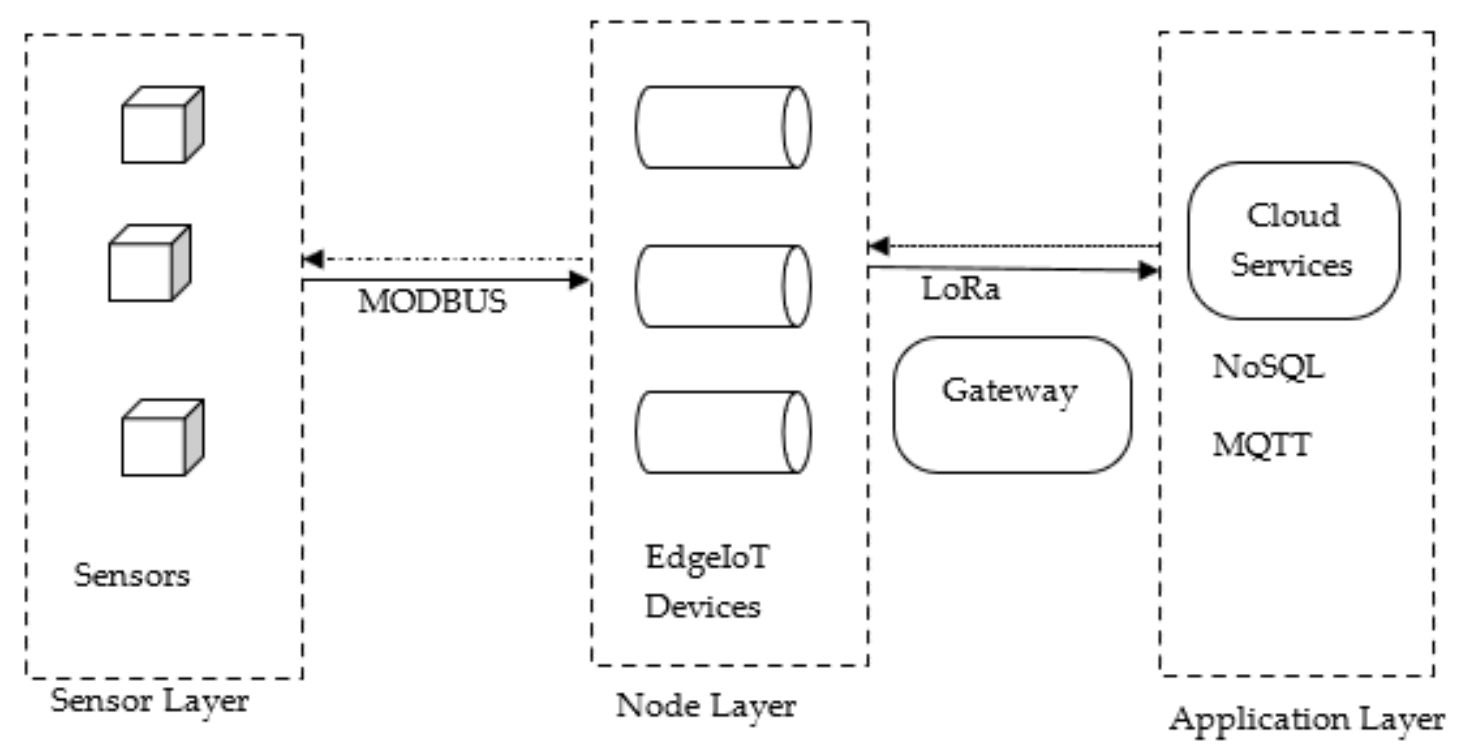

Figure 2. Overview of Groundwater resource IoTs based monitoring system.

\subsection{Groundwater Quantity Monitoring System}

Now, to properly manage, monitor, or model the groundwater resource, the availability of data is very crucial. Furthermore, all the driven-data machine learning techniques could only be used based on the availability of historical data. Hence, an IoT-based and online groundwater quantity monitoring system is necessary for data acquisition, timely access to processed information, to access the impact of drought on groundwater resources, as well as formate decision-making tools, as well as to derive novel drought indicators [229]. The application of a groundwater quantity monitoring system encompasses a large distribution network of monitoring wells with corresponding distributed monitoring sensors utilising different architecture systems [230-231]. Thus, this network of observation wells provides the information about effects of hydrologic stress on the groundwater system [21]. The conventional method of obtaining data from these monitoring wells is by visiting the site once or twice a year to manually collect it at different times. Thus, a lot of laborious manpower, money and time is spent to monitor the groundwater level [231]. Over the years, this conventional manual method has proven to be ineffective because the human in charge may fail to carry out the monitoring. Also, the method lacks real-time monitoring information which is critical for making an urgent decision by a water manager. Thus, Tauro et al suggested that the biggest challenge in groundwater management is how to monitor groundwater level and flow through diverse channels. This 
makes hydrological data loggers to be expensive. Thus, the application of IoT-based lowcost and open-source instrumentation to monitor and manage groundwater quantity systems is one of the needed strong tools. This also allows for the adjustment and tailoring of sensors to a specific hydrological need [239].

Several studies have been carried out to examine groundwater level monitoring in a network of wells. S.T. Prinos et al used groundwater level data to design a real-time groundwater level monitoring network and portrayal of hydrologic data in Southern Florida [232]. The researchers noticed the balance between recharge and discharge is mostly tenuous during droughts. Thus, they analysed 26 years of historical data from three groundwater aquifer systems in South Florida using regression analysis. Through their development, they were able to transmit groundwater timely information to the groundwater managers and the public via the created web portal.

Anumalla et al developed a groundwater monitoring system based on a network of wirelessly linked field-programmable arrays and pressure sensors in Western Nebraska aquifers in the United States of America [229]. These researchers used components such as the Data Acquisition Unit (DAU), the Data Transfer Unit (DTU) and, the Data Processing Unit (DPU) to design this monitoring system. Each unit performs various functions. The DAU is responsible for collecting the data from the sensor and responds to data requests from the DTU. DTU will transport the data from the DAU to the DPU reliably. Finally, the DPU, after gathering the data from sensors, will analyse and store the data for end-use. The system operated on the researchers' argument that timely and quick groundwater data is required to make a critical decision regarding the impact of droughts on groundwater resources.

Two low-cost groundwater level sensor based on Plastic Optical Fibres (POF) was proposed by Esequiel Mesquita et al. In their work, they presented the operation as well as the examination of the impact of using POF sensor on the monitoring of groundwater levels [233]. This work was based on the experimental principle that there is a decrease in signal between the fibre grooves and water in comparison to air. The introduction of grooves in this work increased optical signal strength as the water level also rises as well as vice and versa. The advantages of this experiment are based on its simplicity, low cost, and suitable sensitivity.

A low-cost, low-powered, IoT enabled integrated with energy harvesting groundwater resource monitoring system was designed by Kombo et al [234]. In this study, the authors developed this groundwater monitoring system to produce are real-time data to aid decision making in groundwater resource management in Bandamaji station situated at Zanzibar Tanzania. The brain behind this monitoring system was the Arduino UNO ATmega328P based microcontroller platform which embed with MS5803-14BA and MB280 sensors. The advantage of this prototype lies in its ability to overcome energy barriers by inculcating an automatic energy harvesting technique. This prolonged the life span of this prototype's battery.

Calderwood et al developed a low-cost, open-source wireless sensor network for realtime, scalable groundwater monitoring utilizing cellular telemetry in the South American Subbasin groundwater observatory, located in California, USA [31]. This prototype consists of sensors for groundwater level data acquisition, cellular telemetry units that transfer the acquired data via an open-source data mining pipeline, as well as a visualization web dashboard. Also, the amount of water used was estimated and managed using IoT by Robles et al at a region in Zaragoza, Spain [236]. Through this technique, efficient water monitoring, usage as well as management was achieved. Furthermore, the latest water level data was continuously received by a wireless sensor network developed by Wadekar et al [231]. They were able to visualize and manage an urban area water usage via a smartphone. This system was able to assist the consumers to plan as well as predicting their water usage. Table 4 summarises a few of the related groundwater quantity monitoring systems.

Table 4. Summary of relevant existing groundwater quantity monitoring systems 
Monitoring System and Sensor Type

Unidata Pressure Sensor [229]

802.11 based WLAN

\begin{tabular}{cc}
\hline Plastic Optical Fibres Sensor & MiWiTM-P2 P wireless module \\
[233] & from Microchip Technologies
\end{tabular}

MS5803-02BA and NXP MPX5010 DP [238]

Not Specified

Arduino Pro Mini or Nano

PIC24FJ256DA206 16-bit microcontroller from Microchips Technologies

PIC12F675 microcontroller on sumption and energy harvesting Altera Nios FPGA board were not reported. However, the cost analysis was reported

Salty water affects its performance as well as the temperature calibration is not precise. The details of power consumption analysis were not reported Except for the reported cost analysis, the power consumption analysis was not given

It requires one or more gateways because the single-channel Redesigned MS58030-14BA and MBE280 [234]

LoRa and GSM

Arduino Uno or Mega gateway used limited the number of nodes that can communicate with the LoRa-enabled gateway simultaneously

Due to inertia, the piezoelectric transducer takes some time to
A low-cost ultrasonic Sensor [240]
Texas Instruments CC1200-DK
TI MSP432P\$01R 32-bit ARM and Semetech LoRa iM880A

build up to maximum amplitude;

High power radios;

Water tank reservoirs.

Commercial ultrasonic sensors are inflexible, short maximum distance from the target; and there was no power saving analysis

Apart from the reported detailed cost analysis, the power consumption analysis was not given

\section{Conclusion and Future Directions}

This review presented and discussed the existing trend in groundwater resources management. In the past, most of the existing groundwater resource management models have been combined with optimisation and simulation techniques using appropriate mathematical programming to proffer solutions to challenges within the aquifer. Consequently, the previous surveys have presented a narrow review involving simulation and optimisation management models, however, this review presented a much broader IoTsenabled management perspective. This is because, for any of the management modelling of groundwater resources to be achieved, the measurement of resource data is important. However, part of the general limitations is the uncertainties from input parameters to the system modelling. Furthermore, despite huge research attention towards solving such problems, little research evidence exists concerning achieving computationally efficient and scalable models for groundwater resources management in real-time operations. Although there are various modelling tools as presented in this review, their field applications must be ascertained.

Furthermore, there has been an unprecedented increase in the amount of data generated by electrical sensors in the Internet of Things (IoT) over the years. The application of groundwater resource IoT-based technique is a very useful tool in data acquisition, monitoring, manipulation and management of groundwater resources. This technique combined with GIS has a huge potential in the field of water management. However, IoT data 
are mostly processed via a computing resource situated in a farther data centre location using either internet or cloud computing. Consequently, this has led to insecurity in users' privacy, low latency, and scalability problem. Since the IoT big data are transmitted into the cloud in high volumes, it is necessary to have an efficient and scalable IoT platform to extract valuable information in real-time for groundwater resource management. Also, the existing groundwater level management systems lack large scale in situ management techniques.

For future research directions, the challenges of high computational inefficiency and scalability must be addressed. This will enable the groundwater level management model to achieve computationally efficient and scalability. Also, the current IoT-enabled automated data processing systems for transmitting the generated data from IoT sensors into the centralised cloud are not scalable and efficient. Therefore, there is a need to develop an alternative model for the IoT-enabled groundwater level management model. These are open research directions that should be explored. Although this is a review of existing management models for groundwater resources, this is not all-inclusive. Thus, there is a possibility of missing out on some other publications because it is impractical to review them all. Therefore, these gaps could also be filled with more review publications.

Acknowledgements: The authors acknowledge the research supports received from the Tshwane University of Technology, Pretoria and the Water Research Council (WRC), Pretoria, South Africa.

\section{References}

1. R. Rejani, M. K. Jha, and S. N. Panda, "Simulation-optimization modelling for sustainable groundwater management in a coastal basin of Orissa, India," Water Resources Management, vol. 23, no. 2, pp. 235-263, 2009.

2. X. A. Mary, L. Rose, and K. Rajasekaran, "Continuous And Remote Monitoring Of Ground Water Level Measurement In A Well," International Journal of Water, vol. 12, no. 4, pp. 356-369, 2018.

3. S. Q. Aziz, S. M. Saleh, and I. A. Omar, "Essential Treatment Processes for Industrial Wastewaters and Reusing for Irrigation," Zanco Journal of Pure and Applied Sciences, vol. 31, no. s3, pp. 269-275, 2019.

4. A. Chambel, "The role of groundwater in the management of water resources in the World," Proceedings of the International Association of Hydrological Sciences, vol. 366, p. 107, 2015.

5. R. Taylor et al., "Groundwater and climate change. Nat Clim Chang 3: 322-329," ed, 2013

6. J. Yin and F. T.-C. Tsai, "Saltwater Scavenging Optimization Under Surrogate Uncertainty For A Multi-Aquifer System," Journal of hydrology, vol. 565, pp. 698-710, 2018.

7. J. Yin and F. T.-C. Tsai, "Steady-State Approximate Freshwater-Saltwater Interface In A Two-Horizontal-Well Scavenging System," Journal of Hydrologic Engineering, vol. 24, no. 10, p. 06019008, 2019.

8. A. Motevalli, H. R. Moradi, and S. Javadi, "A Comprehensive Evaluation Of Groundwater Vulnerability To Saltwater Up-Coning And Sea Water Intrusion In A Coastal Aquifer (Case Study: Ghaemshahr-Juybar Aquifer)," Journal of Hydrology, vol. 557, pp. 753-773, 2018.

9. A. Mani, F. T.-C. Tsai, and K. P. Paudel, "Mixed Integer Linear Fractional Programming For Conjunctive Use Of Surface Water And Groundwater," Journal of Water Resources Planning and Management, vol. 142, no. 11, p. 04016045, 2016.

10. B. D. Conway, "Land Subsidence And Earth Fissures In South-Central And Southern Arizona, USA," Hydrogeology Journal, vol. 24, no. 3, pp. 649-655, 2016.

11. P. Castellazzi et al., "Groundwater Depletion In Central Mexico: Use Of Grace And Insar To Support Water Resources Management," Water resources research, vol. 52, no. 8, pp. 5985-6003, 2016.

12. L. E. Erban, S. M. Gorelick, H. A. Zebker, and S. Fendorf, "Release Of Arsenic To Deep Groundwater In The Mekong Delta, Vietnam, Linked To Pumping-Induced Land Subsidence," Proceedings of the National Academy of Sciences, vol. 110, no. 34, pp. 13751-13756, 2013.

13. Y. Yang, X. F. Song, F. D. Zheng, L. C. Liu, and X. J. Qiao, "Simulation Of Fully Coupled Finite Element Analysis Of Nonlinear Hydraulic Properties In Land Subsidence Due To Groundwater Pumping," Environmental Earth Sciences, vol. 73, no. 8, pp. 4191-4199, 2015.

14. W. W. Yeh, "Optimization Methods For Groundwater Modeling And Management," Hydrogeology Journal, vol. 23, no. 6, pp. 1051-1065, 2015.

15. Z. Liu, V. Merwade, and K. Jafarzadegan, "Investigating The Role Of Model Structure And Surface Roughness In Generating Flood Inundation Extents Using One-And Two-Dimensional Hydraulic Models," Journal of Flood Risk Management, vol. 12, no. 1, p. e12347, 2019.

16. K. R. S. R. Raju and G. H. K. Varma, "Knowledge-Based Real-Time Monitoring System For Aquaculture Using IoT," in 2017 IEEE 7th international advance computing conference (IACC), 2017: IEEE, pp. 318-321

17. U. G. Assembly, "Transforming Our World: The 2030 Agenda for Sustainable Development, Resolution Adopted by the General Assembly on 25 September 2015," United Nations, New York, NY, USA, 2015. 
18. M. Khaki, I. Yusoff, and N. Islami, "Simulation of groundwater level through artificial intelligence system," Environment Earth Science, vol. 73, no. 12, pp. 8357-8367, 2015, https://doi.org/10.1007/s1266 5-014-3997-8.

19. Y. Gong, Y. Zhang, S. Lan, and H. Wang, "A Comparative Study of Artificial Neural Networks, Support Vector Machines and Adaptive Neuro-Fuzzy Inference System for Forecasting Groundwater Levels Near Lake Okeechobee, Florida," Water resources management, vol. 30, no. 1, pp. 375-391, 2016.

20. A. Verma and T. Singh, "Prediction of Water Quality from Simple Field Parameters," Environmental earth sciences, vol. 69, no. 3, pp. 821-829, 2013.

21. C. J. Taylor and W. M. Alley, Ground-Water-Level Monitoring And The Importance Of Long-Term Water-Level Data (no. 1217-2002). US Department of the Interior, US Geological Survey, 2002.

22. A. Singh, "Simulation And Optimization Modeling For The Management Of Groundwater Resources. II: Combined Applications," Journal of Irrigation and Drainage Engineering, vol. 140, no. 4, p. 04014002, 2014.

23. Y. Gong, Z. Wang, G. Xu, and Z. Zhang, "A Comparative Study of Groundwater Level Forecasting Using Data-Driven Models Based on Ensemble Empirical Mode Decomposition," Water, vol. 10, no. 6, p. 730, 2018, doi: 10.3390/w10060730.

24. F.-J. Chang, L.-C. Chang, C.-W. Huang, and I.-F. Kao, "Prediction Of Monthly Regional Groundwater Levels Through Hybrid Soft-Computing Techniques," Journal of Hydrology, vol. 541, pp. 965-976, 2016.

25. J. Chang, G. Wang, and T. Mao, "Simulation And Prediction Of Suprapermafrost Groundwater Level Variation In Response To Climate Change Using A Neural Network Model," Journal of Hydrology, vol. 529, pp. 1211-1220, 2015.

26. M. J. Asher, B. F. Croke, A. J. Jakeman, and L. J. Peeters, "A Review Of Surrogate Models And Their Application To Groundwater Modeling," Water Resources Research, vol. 51, no. 8, pp. 5957-5973, 2015.

27. H. Diersch, "FEFLOW Finite Element Subsurface Flow And Transport Simulation System Reference Manual," WASY Institute for Water Resources Planning and Systems Research, Berlin, p. 292, 2005.

28. A. Harbaugh, "MODFLOW-2005, The Us Geological Survey Modular Groundwater Model: The Groundwater Flow Process," U.S.Geological Survey Technology Methods, vol. 6-A16, pp. 1-99, 2005.

29. J. Doherty and C. T. Simmons, "Groundwater Modelling In Decision Support: Reflections On A Unified Conceptual Framework," Hydrogeology Journal, vol. 21, no. 7, pp. 1531-1537, 2013.

30. P. Leube, W. Nowak, and G. Schneider, "Temporal Moments Revisited: Why There Is No Better Way For Physically Based Model Reduction In Time," Water Resource Res, vol. 48, no. W11527, 2012, doi: 10.1029/2012WR011973

31. A. J. Calderwood, R. A. Pauloo, A. M. Yoder, and G. E. Fogg, "Low-Cost, Open Source Wireless Sensor Network for Real-Time, Scalable Groundwater Monitoring," Water, vol. 12, no. 4, p. 1066, 2020.

32. D. P. Ahlfeld and G. Baro-Montes, "Solving Unconfined Groundwater Flow Management Problems With Successive Linear Programming," Journal of water resources planning and management, vol. 134, no. 5, pp. 404-412, 2008.

33. R. Peralta, B. Timani, and R. Das, "Optimizing Safe Yield Policy Implementation," Water resources management, vol. 25, no. 2, pp. 483-508, 2011.

34. J. Xu, Y. Tu, and Z. Zeng, "Bilevel Optimization Of Regional Water Resources Allocation Problem Under Fuzzy Random Environment," Journal of Water Resources Planning and Management, vol. 139, no. 3, pp. 246-264, 2013.

35. F. T.-C. Tsai, V. Katiyar, D. Toy, and R. A. Goff, "Conjunctive Management Of Large-Scale Pressurized Water Distribution And Groundwater Systems In Semi-Arid Area With Parallel Genetic Algorithm," Water resources management, vol. 23, no. 8, p. 1497, 2009.

36. M. Ayvaz and A. Elci, "A Groundwater Management Tool For Solving The Pumping Cost Minimization," 2013.

37. G. E. Kifanyi, J. M. Ndambuki, and S. N. Odai, "A Quantitative Groundwater Resource Management Under Uncertainty Using A Retrospective Optimization Framework," Sustainability, vol. 9, no. 1, p. 2, 2017.

38. M. Li, P. Guo, and C. Ren, "Water Resources Management Models Based On Two-Level Linear Fractional Programming Method Under Uncertainty," Journal of Water Resources Planning and Management, vol. 141, no. 9, p. 05015001, 2015.

39. S. Emamgholizadeh, K. Moslemi, and G. Karami, "Prediction the groundwater level of bastam plain (Iran) by an artificial neural network (ANN) and adaptive neuro-fuzzy inference system (ANFIS)," Water Resource Management, vol. 28, no. 15, pp. 54335446, 2014, https://doi.org/10.1007/s11269-014-0810-0.

40. E. Fallah-Mehdipour, O. B. Haddad, and M. Mariño, "Prediction and simulation of monthly groundwater levels by genetic programming," Journal of Hydro-Environment Research, vol. 7, no. 4, pp. 253-260, 2013.

41. G. Fu et al., "Attributing variations of temporal and spatial groundwater recharge: A statistical analysis of climatic and nonclimatic factors," Journal of hydrology, vol. 568, pp. 816-834, 2019.

42. Z. He, Y. Zhang, Q. Guo, and X. Zhao, "Comparative study of artificial neural networks and wavelet artificial neural networks for groundwater depth data forecasting with various curve fractal dimensions," Water Resources Management, vol. 28, no. 15, pp. 5297-5317, 2014, https://doi.org/10.1007/s11269-014-0802-0.

43. S. Hosseini and N. Mahjouri, "Integrating support vector regression and a geomorphologic artificial neural network for daily rainfall-runoff modelling," Applied Soft Comput, no. 38, pp. 329-345, 2016, https://doi.org/10.1016/j.asoc.2015.09.049.

44. N.-e.-a. Husna, S. H. Bari, M. M. Hussain, M. T. Ur-Rahman, and M. Rahman, "Groundwater level prediction using artificial neural network," International Journal of Hydrology Science and Technology, vol. 6, no. 4, pp. 371-381, 2016.

45. K. Kenda et al., "Groundwater Modeling With Machine Learning Techniques: Ljubljana Polje Aquifer," in Multidisciplinary Digital Publishing Institute Proceedings, 2018, vol. 2, no. 11, p. 697.

46. K. Khosravi, M. Panahi, and D. T. Bui, "Spatial prediction of groundwater spring potential mapping based on an adaptive neuro-fuzzy inference system and metaheuristic optimization," Hydrology E Earth System Sciences, vol. 22, no. 9, 2018. 
47. O. Kisi, A. Azad, H. Kashi, A. Saeedian, S. A. A. Hashemi, and S. Ghorbani, "Modeling groundwater quality parameters using hybrid neuro-fuzzy methods," Water resources management, vol. 33, no. 2, pp. 847-861, 2019.

48. O. Kisi, A. Keshavarzi, J. Shiri, M. Zounemat-Kermani, and E.-S. E. Omran, "Groundwater Quality Modeling Using NeuroParticle Swarm Optimization And Neuro-Differential Evolution Techniques," Hydrology Research, vol. 48, no. 6, pp. 1508-1519, 2017.

49. V. Moosavi, M. Vafakhah, B. Shirmohammadi, and N. Behnia, "A wavelet-ANFIS hybrid model for groundwater level forecasting for different prediction periods," Water resources management, vol. 27, no. 5, pp. 1301-1321, 2013.

50. S. M. T. Mustafa et al., "Multi-model approach to quantify groundwater-level prediction uncertainty using an ensemble of global climate models and multiple abstraction scenarios," Hydrology and Earth System Sciences, vol. 23, no. 5, pp. $2279-2303,2019$.

51. J. Ndambuki, F. Otieno, C. Stroet, and E. Veling, "Groundwater management under uncertainty: a multi-objective approach," WATER SA-PRETORIA-, vol. 26, no. 1, pp. 35-42, 2000.

52. J. M. Ndambuki, "Multi-Objective Groundwater Quantity Management: A Stochastic Approach," Doctoral, Water Resources Engineering Project, Delft University, The Netherlands, 2001.

53. B. Shirmohammadi, M. Vafakhah, V. Moosavi, and A. Moghaddamnia, "Application of several data-driven techniques for predicting groundwater level," Water Resources Management, vol. 27, no. 2, pp. 419-432, 2013.

54. Taormina R, Chau K, and S. R, "Artificial neural network simulation of hourly groundwater levels in a coastal aquifer system of the Venice lagoon," Eng Appl Artif Intell, vol. 25, no. 8, pp. 1670-1676, 2015, https://doi.org/10.1016/j.engappai.2012.02.009.

55. M. Valipour, M. E. Banihabib, and S. M. R. Behbahani, "Comparison of the ARMA, ARIMA, and the autoregressive artificial neural network models in forecasting the monthly inflow of Dez dam reservoir," Journal of hydrology, vol. 476, pp. 433-441, 2013.

56. W. Xuanhui, L. Tailian, Z. Xilai, P. Hui, X. Jia, and Z. Bo, "Short-term prediction of groundwater level using improved random forest regression with a combination of random features," Applied Water Science, vol. 8, no. 125, pp. 1-12, 2018, doi: doi.org/10.1007/s13201-018-0742-6.

57. J. Yin, H. V. Pham, and F. T.-C. Tsai, "Multiobjective Spatial Pumping Optimization for Groundwater Management in a Multiaquifer System," Journal of Water Resources Planning and Management, vol. 146, no. 4, p. 04020013, 2020.

58. S. Emamgholizadeh, K. Moslemi, and G. Karami, "Prediction the Groundwater Level of Bastam Plain (Iran) by Artificial Neural Network (ANN) and Adaptive Neuro-Fuzzy Inference System (ANFIS)," Water resources management, vol. 28, no. 15, pp. 54335446, 2014.

59. S. Sun, C. Zhang, and G. Yu, "A Bayesian Network Approach to Traffic Flow Forecasting," IEEE Transactions on intelligent transportation systems, vol. 7, no. 1, pp. 124-132, 2006.

60. S. Sun and X. Xu, "Variational Inference for Infinite Mixtures of Gaussian Processes with Applications to Traffic Flow Prediction," IEEE Transactions on Intelligent Transportation Systems, vol. 12, no. 2, pp. 466-475, 2011.

61. H. Yoon, S.-C. Jun, Y. Hyun, G.-O. Bae, and K.-K. Lee, "A comparative study of artificial neural networks and support vector machines for predicting groundwater levels in a coastal aquifer," Journal of Hydrology, vol. 396, no. 1-2, pp. 128-138, 2011.

62. R. Li, G. Ou, M. Pun, and L. Larson, "Evaluation Of Groundwater Resources In Response To Agricultural Management Scenarios In The Central Valley, California," Journal of Water Resources Planning and Management, vol. 144, no. 12, p. $04018078,2018$.

63. S. M. T. Mustafa et al., "Multi-Model Approach To Quantify Groundwater-Level Prediction Uncertainty Using An Ensemble Of Global Climate Models And Multiple Abstraction Scenarios," Hydrology and Earth System Sciences, 2019.

64. M. F. Bierkens and Y. Wada, "Non-Renewable Groundwater Use And Groundwater Depletion: A Review," Environmental Research Letters, vol. 14, no. 6, p. 063002, 2019.

65. Y. Wada et al., "Fate Of Water Pumped From Underground And Contributions To Sea-Level Rise," Nature Climate Change, vol. 6, no. 8, pp. 777-780, 2016.

66. Y. Wada, "Modelling Groundwater Depletion At Regional And Global Scales: Present State And Future Prospects," Surveys in Geophysics, vol. 37, no. 2, pp. 419-451, 2016.

67. Y. Wada and M. F. Bierkens, "Sustainability Of Global Water Use: Past Reconstruction And Future Projections," Environmental Research Letters, vol. 9, no. 10, p. 104003, 2014.

68. Y. Wada, D. Wisser, and M. F. Bierkens, "Global Modeling Of Withdrawal, Allocation And Consumptive Use Of Surface Water And Groundwater Resources," Earth System Dynamics Discussions, vol. 5, no. 1, pp. 15-40, 2014.A. S. Richey, B. F. Thomas, M. H. Lo, J. S. Famiglietti, S. Swenson, and M. Rodell, "Uncertainty In Global Groundwater Storage Estimates In A T Otal G Roundwater S Tress Framework," Water Resources Research, vol. 51, no. 7, pp. 5198-5216, 2015.

69. A. S. Richey, B. F. Thomas, M. H. Lo, J. S. Famiglietti, S. Swenson, and M. Rodell, "Uncertainty In Global Groundwater Storage Estimates In A T Otal G Roundwater S Tress Framework," Water Resources Research, vol. 51, no. 7, pp. 5198-5216, 2015.

70. M. Rodell et al., "Emerging trends in global freshwater availability (vol 557, pg 651, 2018)," Nature, vol. 565, no. 7739, pp. E7E7, 2019.

71. G. Premsankar, M. Di Francesco, and T. Taleb, "Edge Computing for the Internet of Things: A case study," IEEE Internet of Things Journal, vol. 5, no. 2, pp. 1275-1284, 2018.

72. H. Li, K. Ota, and M. Dong, "Learning IoT in edge: Deep learning for the Internet of Things with edge computing," IEEE Network, vol. 32, no. 1, pp. 96-101, 2018.

73. X. Sun and N. Ansari, "EdgeIoT: Mobile edge computing for the Internet of Things," IEEE Communications Magazine, vol. 54, no. 12, pp. 22-29, 2016.

74. N. Kaur and S. K. Sood, "An energy-efficient architecture for the Internet of Things (IoT)," IEEE Systems Journal, vol. 11, no. 2, pp. 796-805, 2015. 
75. P. Corcoran and S. K. Datta, "Mobile-edge computing and the Internet of Things for consumers: Extending cloud computing and services to the edge of the network," IEEE Consumer Electronics Magazine, vol. 5, no. 4, pp. 73-74, 2016.

76. M. G. Eltarabily, A. M. Negm, C. Yoshimura, and O. C. Saavedra, "Modeling The Impact Of Nitrate Fertilizers On Groundwater Quality In The Southern Part Of The Nile Delta, Egypt," Water Science and Technology: Water Supply, vol. 17, no. 2, pp. 561570, 2017.

77. S. M. Gorelick, C. I. Voss, P. E. Gill, W. Murray, M. A. Saunders, and M. H. Wright, "Aquifer Reclamation Design: The Use Of Contaminant Transport Simulation Combined With Nonlinear Programing," Water Resources Research, vol. 20, no. 4, pp. 415427, 1984.

78. E. Gordon, U. Shamir, and J. Bensabat, "Optimal Management Of A Regional Aquifer Under Salinization Conditions," Water Resources Research, vol. 36, no. 11, pp. 3193-3203, 2000.

79. F. Heydari, B. Saghafian, and M. Delavar, "Coupled Quantity-Quality Simulation-Optimization Model For Conjunctive SurfaceGroundwater Use," Water Resources Management, vol. 30, no. 12, pp. 4381-4397, 2016.

80. A. Izady et al., "Groundwater Conceptualization And Modeling Using Distributed Swat-Based Recharge For The Semi-Arid Agricultural Neishaboor Plain, Iran," Hydrogeology Journal, vol. 23, no. 1, pp. 47-68, 2015.

81. M. T. Ayvaz, "Application Of Harmony Search Algorithm To The Solution Of Groundwater Management Models," Advances in Water Resources, vol. 32, no. 6, pp. 916-924, 2009.

82. M. T. Ayvaz and H. Karahan, "A Simulation/Optimization Model For The Identification Of Unknown Groundwater Well Locations And Pumping Rates," Journal of Hydrology, vol. 357, no. 1-2, pp. 76-92, 2008.

83. C. A. C. Coello, G. T. Pulido, and M. S. Lechuga, "Handling Multiple Objectives With Particle Swarm Optimization," IEEE Transactions on evolutionary computation, vol. 8, no. 3, pp. 256-279, 2004.

84. H. A. El-Ghandour and E. Elbeltagi, "Optimal Groundwater Management Using Multiobjective Particle Swarm With A New Evolution Strategy," Journal of Hydrologic Engineering, vol. 19, no. 6, pp. 1141-1149, 2014.

85. S. M. Gorelick, "A Review Of Distributed Parameter Groundwater Management Modeling Methods," Water Resources Research, vol. 19, no. 2, pp. 305-319, 1983.

86. J. D. Bredehoeft, E. G. Reichard, and S. M. Gorelick, "If It Works, Don't Fix It: Benefits From Regional Ground-Water Management," Groundwater Models for Resources Analysis and Management, pp. 103-124, 1995.

87. B. J. Wagner, "Recent Advances In Simulation-Optimization Groundwater Management Modeling," Reviews of Geophysics, vol. 33, no. S2, pp. 1021-1028, 1995.

88. A. Singh, "Simulation And Optimization Modeling For The Management Of Groundwater Resources. I: Distinct Applications," Journal of Irrigation and Drainage Engineering, vol. 140, no. 4, p. 04013021, 2014.

89. A. Singh, "Groundwater Resources Management Through The Applications Of Simulation Modeling: A Review," Science of the Total Environment, vol. 499, pp. 414-423, 2014.

90. S. M. Gorelick, "Large Scale Nonlinear Deterministic And Stochastic Optimization: Formulations Involving Simulation Of Subsurface Contamination," Mathematical Programming, vol. 48, no. 1-3, pp. 19-39, 1990.

91. L. AV and G. S, "Sequential Gradient-Restoration Algorithm For The Optimization Of A Nonlinear Constrained Function," Journal of the Astronautical Sciences, Special Issue on Numerical Methods in Optimization, vol. 30, no. 2, 1982.

92. M. A. Dawoud, M. M. Darwish, and M. M. El-Kady, "GIS-Based Groundwater Management Model For Western Nile Delta," Water Resources Management, vol. 19, no. 5, pp. 585-604, 2005.

93. N. Mylopoulos, Y. Mylopoulos, D. Tolikas, and N. Veranis, "Groundwater Modeling And Management In A Complex LakeAquifer System," Water resources management, vol. 21, no. 2, pp. 469-494, 2007.

94. X. Xu, G. Huang, Z. Qu, and L. S. Pereira, "Using MODFLOW and GIS to Assess Changes In Groundwater Dynamics In Response To Water Saving Measures In Irrigation Districts Of The Upper Yellow River Basin," Water Resources Management, vol. 25, no. 8, pp. 2035-2059, 2011.

95. M. M. Rajabi and H. Ketabchi, "Uncertainty-Based Simulation-Optimization Using Gaussian Process Emulation: Application To Coastal Groundwater Management," Journal of Hydrology, vol. 555, pp. 518-534, 2017.

96. H. H. Cooper Jr, "The Equation Of Groundwater Flow In Fixed And Deforming Coordinates," Journal of Geophysical Research, vol. 71, no. 20, pp. 4785-4790, 1966.

97. I. Remson, G. M. Hornberger, and F. J. Molz, "Numerical Methods In Subsurface Hydrology," 1971.

98. G. F. Pinder and J. Bredehoeft, "Application Of The Digital Computer For Aquifer Evaluation," Water Resources Research, vol. 4, no. 5, pp. 1069-1093, 1968.

99. O. Rahmati et al., "Predicting Uncertainty Of Machine Learning Models For Modelling Nitrate Pollution Of Groundwater Using Quantile Regression And UNEEC Methods," Science of the Total Environment, vol. 688, pp. 855-866, 2019.

100. R. Barzegar, A. A. Moghaddam, R. Deo, E. Fijani, and E. Tziritis, "Mapping Groundwater Contamination Risk Of Multiple Aquifers Using Multi-Model Ensemble Of Machine Learning Algorithms," Science of the total environment, vol. 621, pp. 697-712, 2018.

101. P. Venkataraman, Applied optimization with MATLAB programming. John Wiley \& Sons, 2009.

102. J. Rosen, "The gradient projection method for nonlinear programming. Part II. Nonlinear constraints," Journal of the Society for Industrial and Applied Mathematics, vol. 9, no. 4, pp. 514-532, 1961.

103. T. Hastie, R. Tibshirani, and J. Friedman, The Elements Of Statistical Learning: Data Mining, Inference, And Prediction, 2nd ed. New York, NY, USA: Springer Science \& Business Media, 2017.

104. The Elements Of Statistical Learning: Data Mining, Inference, And Prediction, Wiley Online Library, 2010.

105. L. Breiman, "Random Forests," Machine learning, vol. 45, no. 1, pp. 5-32, 2001. 
106. L. Breiman, "Random Forests," UC Berkeley TR567, 1999.

107. A. Cutler, D. R. Cutler, and J. R. Stevens, "Random Forests," in Ensemble machine learning: Springer, 2012, pp. 157-175.

108. T. Zhang, "Sequential Greedy Approximation For Certain Convex Optimization Problems," IEEE Transactions on Information Theory, vol. 49, no. 3, pp. 682-691, 2003.

109. J. H. Friedman, "Greedy Function Approximation: A Gradient Boosting Machine," Annals of statistics, pp. 1189-1232, 2001.

110. S. Haykin, Neural Networks, a Comprehensive Foundation. Upper Saddle River, New Jersey: PreIncntice-Hall 1999, pp. 161-175.

111. S. Samarasinghe, "Neural Networks for Applied Sciences and Engineering: From Fundamentals to Complex," Pattern Recognition, 2006.

112. ASCE, "Artificial Neural Networks in Hydrology. I: Preliminary Concepts," Journal of Hydrologic Engineering, vol. 5, no. 2, pp. 115-123, 2000a.

113. ASCE, "Artificial neural networks in hydrology. II: Hydrologic applications," Journal of Hydrologic Engineering, vol. 5, no. 2, pp. 124-137, 2000b.

114. S. Cho et al., "Factors Affecting Algal Blooms in a Man-made Lake and Prediction using an Artificial Neural Network," Measurement, vol. 53, pp. 224-233, 2014.

115. Z. Z. Latt, H. Wittenberg, and B. Urban, "Clustering Hydrological Homogeneous Regions and Neural Network Based Index Flood Estimation for Ungauged Catchments: an Example of the Chindwin River in Myanmar," Water resources management, vol. 29, no. 3, pp. 913-928, 2015.

116. P. Nastos, A. Paliatsos, K. Koukouletsos, I. Larissi, and K. Moustris, "Artificial Neural Networks Modeling for Forecasting the Maximum Daily Total Precipitation at Athens, Greece," Atmospheric Research, vol. 144, pp. 141-150, 2014.

117. H. A. Afan, A. El-Shafie, Z. M. Yaseen, M. M. Hameed, W. H. M. W. Mohtar, and A. Hussain, "ANN Based Sediment Prediction Model Utilizing Different Input Scenarios," Water resources management, vol. 29, no. 4, pp. 1231-1245, 2015.

118. Z. He, X. Wen, H. Liu, and J. Du, "A Comparative Study of Artificial Neural Network, Adaptive Neuro-Fuzzy Inference System and Support Vector Machine for Forecasting River Flow in the Semiarid Mountain Region," Journal of Hydrology, vol. 509, pp. 379-386, 2014

119. J.-S. Jang, "ANFIS: Adaptive-Network-Based Fuzzy Inference System," IEEE transactions on systems, man, and cybernetics, vol. 23, no. 3, pp. 665-685, 1993.

120. J.-S. R. Jang, C.-T. Sun, and E. Mizutani, "Neuro-Fuzzy And Soft Computing-A Computational Approach To Learning And Machine Intelligence ", vol. 42IEEE Transactions on automatic control: Prentice-Hall, 1997, pp. 1482-1484.

121. M. K. Goyal, B. Bharti, J. Quilty, J. Adamowski, and A. Pandey, "Modeling Of Daily Pan Evaporation In Sub Tropical Climates Using ANN, LS-SVR, Fuzzy Logic, and ANFIS," Expert systems with applications, vol. 41, no. 11, pp. 5267-5276, 2014.

122. J. A. Awan and D.-H. Bae, "Improving ANFIS Based Model For Long-Term Dam Inflow Prediction By Incorporating Monthly Rainfall Forecasts," Water resources management, vol. 28, no. 5, pp. 1185-1199, 2014.

123. A. Hipni, A. El-shafie, A. Najah, O. A. Karim, A. Hussain, and M. Mukhlisin, "Daily Forecasting Of Dam Water Levels: Comparing A Support Vector Machine (SVM) Model With Adaptive Neuro-Fuzzy Inference System (ANFIS)," Water resources management, vol. 27, no. 10, pp. 3803-3823, 2013.

124. H. Vernieuwe, O. Georgieva, B. De Baets, V. R. Pauwels, N. E. Verhoest, and F. P. De Troch, "Comparison Of Data-Driven Takagi-Sugeno Models Of Rainfall-Discharge Dynamics," Journal of Hydrology, vol. 302, no. 1-4, pp. 173-186, 2005.

125. A. Moghaddamnia, M. G. Gousheh, J. Piri, S. Amin, and D. Han, "Evaporation Estimation Using Artificial Neural Networks And Adaptive Neuro-Fuzzy Inference System Techniques," Advances in Water Resources, vol. 32, no. 1, pp. 88-97, 2009.

126. J. Shiri and Ö. Kişi, "Comparison Of Genetic Programming With Neuro-Fuzzy Systems For Predicting Short-Term Water Table Depth Fluctuations," Computers \& Geosciences, vol. 37, no. 10, pp. 1692-1701, 2011.

127. V. N. Vapnik, The Nature Of Statistical Learning (Theory). New York, Inc: Springer-Verlag 1995.

128. V. Vapnik, Statistical Learning Theory (no. 2). New York: Wiley, 1998, p. 624.

129. X. Wen, J. Si, Z. He, J. Wu, H. Shao, and H. Yu, "Support-Vector-Machine-Based Models For Modeling Daily Reference Evapotranspiration With Limited Climatic Data In Extreme Arid Regions," Water Resources Management, vol. 29, no. 9, pp. 3195-3209, 2015.

130. S. Ch, N. Anand, B. K. Panigrahi, and S. Mathur, "Streamflow Forecasting by SVM with Quantum Behaved Particle Swarm Optimization," Neurocomputing, vol. 101, pp. 18-23, 2013.

131. M. Çimen and O. Kisi, "Comparison Of Two Different Data-Driven Techniques In Modeling Lake Level Fluctuations In Turkey," Journal of Hydrology, vol. 378, no. 3-4, pp. 253-262, 2009.

132. R. Noori et al., "Assessment Of Input Variables Determination On The SVM Model Performance Using PCA, Gamma Test, And Forward Selection Techniques For Monthly Stream Flow Prediction," Journal of hydrology, vol. 401, no. 3-4, pp. 177-189, 2011.

133. H. Tabari, O. Kisi, A. Ezani, and P. H. Talaee, "SVM, ANFIS, Regression And Climate Based Models For Reference Evapotranspiration Modeling Using Limited Climatic Data In A Semi-Arid Highland Environment," Journal of Hydrology, vol. 444, pp. 7889, 2012.

134. Y.-H. Wang, C.-H. Yeh, H.-W. V. Young, K. Hu, and M.-T. Lo, "On The Computational Complexity Of The Empirical Mode Decomposition Algorithm," Physica A: Statistical Mechanics and its Applications, vol. 400, pp. 159-167, 2014.

135. A. Humeau-Heurtier, P. Abraham, and G. Mahé, "Analysis Of Laser Speckle Contrast Images Variability Using A Novel Empirical Mode Decomposition: Comparison Of Results With Laser Doppler Flowmetry Signals Variability," IEEE transactions on medical imaging, vol. 34, no. 2, pp. 618-627, 2015.

136. X. Wang, T. Liu, X. Zheng, H. Peng, J. Xin, and B. Zhang, "Short-Term Prediction Of Groundwater Level Using Improved Random Forest Regression With A Combination Of Random Features," Applied Water Science, vol. 8, no. 5, p. 125, 2018. 
137. N. Raghavendra and P. Deka, "Support vector machine applications in the field of hydrology: a review," Appl Soft Comput, vol. 19, pp. 372-386, 2014, https://doi.org/10.1016/j.asoc.2014.02.002.

138. H. Yoon, Y. Hyun, K. Ha, K.-K. Lee, and G.-B. Kim, "A method to improve the stability and accuracy of ANN- and SVM-based time series models for long-term groundwater level predictions," Computer Geoscience, no. 90, pp. 144-155, 2016, https://doi.org/10.1016/j.cageo.2016.03.002.

139. Z. Wu and N. E. Huang, "Ensemble empirical mode decomposition: a noise-assisted data analysis method," Advances in adaptive data analysis, vol. 1, no. 01, pp. 1-41, 2009.

140. C. H. Lee and R. T. S. Cheng, "On Seawater Encroachment In Coastal Aquifers," Water Resources Research, vol. 10, no. 5, pp. 10391043, 1974.

141. H. N. Tyson and E. M. Weber, "Use Of Electronic Computer In The Simulation Of Dynamic Behaviour Of Groundwater Basin," in ASCE Water Resources Engineering Conference. Milwaukee, Wisconsin, 1963.

142. G. D'Urso, M. Menenti, and A. Santini, "Regional Application Of One-Dimensional Water Flow Models For Irrigation Management," Agricultural Water Management, vol. 40, no. 2-3, pp. 291-302, 1999.

143. G. W. Kite and P. Droogers, Comparing Estimates Of Actual Evapotranspiration From Satellites, Hydrological Models, And Field Data: A Case Study From Western Turkey. IWMI, 2000.

144. J. Van Dam et al., "Assessing Options To Increase Water Productivity In Irrigated River Basins Using Remote Sensing And Modelling Tools," Water resources development, vol. 22, no. 1, pp. 115-133, 2006.

145. A. E. Hassan, "Validation Of Numerical Ground Water Models Used To Guide Decision Making," Groundwater, vol. 42, no. 2, pp. 277-290, 2004.

146. C. D. Pint, R. J. Hunt, and M. P. Anderson, "Flowpath Delineation And Ground Water Age, Allequash Basin, Wisconsin," Groundwater, vol. 41, no. 7, pp. 895-902, 2003.

147. T. J. Budge and J. M. Sharp Jr, "Modeling The Usefulness Of Spatial Correlation Analysis On Karst Systems," Groundwater, vol. 47, no. 3, pp. 427-437, 2009.

148. Y. Zhu, L. Shi, J. Yang, J. Wu, and D. Mao, "Coupling Methodology And Application Of A Fully Integrated Model For Contaminant Transport In The Subsurface System," Journal of hydrology, vol. 501, pp. 56-72, 2013.

149. P. Van Walsum and A. Veldhuizen, "Integration Of Models Using Shared State Variables: Implementation In The Regional Hydrologic Modelling System SIMGRO," Journal of Hydrology, vol. 409, no. 1-2, pp. 363-370, 2011.

150. Z. Yang, W. Lu, Y. Long, and P. Li, "Application And Comparison Of Two Prediction Models For Groundwater Levels: A Case Study In Western Jilin Province, China," Journal of Arid Environments, vol. 73, no. 4-5, pp. 487-492, 2009.

151. M. P. Anderson, W. W. Woessner, and R. J. Hunt, Applied Groundwater Modeling: Simulation Of Flow And Advective Transport. Academic Press, 2015.

152. L. F. Konikow and J. D. Bredehoeft, "Ground-Water Models Cannot Be Validated," Advances in water resources, vol. 15, no. 1, pp. 75-83, 1992.

153. A. Singh and S. N. Panda, "Optimization And Simulation Modelling For Managing The Problems Of Water Resources," Water resources management, vol. 27, no. 9, pp. 3421-3431, 2013.

154. E. P. Poeter and M. C. Hill, "Inverse Models: A Necessary Next Step In Ground-Water Modeling," Groundwater, vol. 35, no. 2, pp. 250-260, 1997.

155. E. Poeter, "All Models Are Wrong, How Do We Know Which Are Useful," Ground Water, vol. 45, no. 4, pp. 390-391, 2007.

156. H. A. Michael and C. I. Voss, "Evaluation Of The Sustainability Of Deep Groundwater As An Arsenic-Safe Resource In The Bengal Basin," Proceedings of the National Academy of Sciences, vol. 105, no. 25, pp. 8531-8536, 2008.

157. L. Zhang, N. Potter, K. Hickel, Y. Zhang, and Q. Shao, "Water Balance Modeling Over Variable Time Scales Based On The Budyko Framework-Model Development And Testing," Journal of Hydrology, vol. 360, no. 1-4, pp. 117-131, 2008.

158. J. J. Harou, M. Pulido-Velazquez, D. E. Rosenberg, J. Medellín-Azuara, J. R. Lund, and R. E. Howitt, "Hydro-Economic Models: Concepts, Design, Applications, And Future Prospects," Journal of Hydrology, vol. 375, no. 3-4, pp. 627-643, 2009.

159. D. Raes, "UPFLOW Water Movement in a Soil Profile from a Shallow Water Table to the Topsoil (Capillary Rise)," Reference Manual, Department of Land Management, Leuven, 2009.

160. S. M. Wondzell, J. LaNier, and R. Haggerty, "Evaluation Of Alternative Groundwater Flow Models For Simulating Hyporheic Exchange In A Small Mountain Stream," Journal of Hydrology, vol. 364, no. 1-2, pp. 142-151, 2009.

161. S. M. Wondzell, M. N. Gooseff, and B. L. McGlynn, "An Analysis Of Alternative Conceptual Models Relating Hyporheic Exchange Flow To Diel Fluctuations In Discharge During Baseflow Recession," Hydrological Processes: An International Journal, vol. 24, no. 6, pp. 686-694, 2010.

162. C.-C. Yang, L.-C. Chang, C.-S. Chen, and M.-S. Yeh, "Multi-Objective Planning For Conjunctive Use Of Surface And Subsurface Water Using Genetic Algorithm And Dynamics Programming," Water resources management, vol. 23, no. 3, pp. 417-437, 2009.

163. W. E. Sanford and J. P. Pope, "Current Challenges Using Models To Forecast Seawater Intrusion: Lessons From The Eastern Shore Of Virginia, USA," Hydrogeology Journal, vol. 18, no. 1, pp. 73-93, 2010.

164. M. Sherif, A. Kacimov, A. Javadi, and A. A. Ebraheem, "Modeling Groundwater Flow And Seawater Intrusion In The Coastal Aquifer Of Wadi Ham, UAE," Water resources management, vol. 26, no. 3, pp. 751-774, 2012.

165. Y.-S. Su, C.-F. Ni, W.-C. Li, I.-H. Lee, and C.-P. Lin, "Applying Deep Learning Algorithms To Enhance Simulations Of LargeScale Groundwater Flow in IoTs," Applied Soft Computing, vol. 92, p. 106298, 2020.

166. S. Narendran, P. Pradeep, and M. V. Ramesh, "An Internet of Things (IoT) based Sustainable Water Management," in 2017 IEEE Global Humanitarian Technology Conference (GHTC), 2017: IEEE, pp. 1-6. 
167. H. Manguinhas, B. Martins, J. Borbinha, and W. Siabato, "A Geo-Temporal Web Gazetteer Service Integrating Data From Multiple Sources," in 3rd IEEE International Conference on Digital Information Management, 2008.

168. S. Talari, M. Shafie-Khah, P. Siano, V. Loia, A. Tomasetti, and J. P. Catalão, "A Review Of Smart Cities Based On The Internet Of Things Concept," Energies, vol. 10, no. 4, p. 421, 2017.

169. W. R. Jones, M. J. Spence, A. W. Bowman, L. Evers, and D. A. Molinari, "GWSDAT-GroundWater Spatiotemporal Data Analysis Tool," arXiv preprint arXiv:1310.8158, 2014.

170. S. Laraichi, A. Hammani, and A. Bouignane, "Data Integration As The Key To Building A Decision Support System For Groundwater Management: Case Of Saiss Aquifers, Morocco," Groundwater for Sustainable Development, vol. 2, pp. 7-15, 2016.

171. J. van der Gun, "Data, Information, Knowledge And Diagnostics On Groundwater," Advances in groundwater governance, pp. 193-213, 2018

172. I. G. R. A. C. (IGRAC), "Groundwater in a changing world," in "IGRAC Strategy " IGRAC, Delft, The Netherlands, 2019 , vol. 2019-23. [Online]. Available: https://www.un-igrac.org/resource/igrac-strategy-2019-23-groundwater-changing-world

173. J. S. Famiglietti, "The Global Groundwater Crisis," Nature Climate Change, vol. 4, no. 11, pp. 945-948, 2014.

174. J. Famiglietti, A. Cazenave, A. Eicker, J. Reager, M. Rodell, and I. Velicogna, "Satellites Provide The Big Picture," Science (New York, NY), vol. 349, no. 6249, pp. 684-685, 2015.

175. N. Vijayakumar and Ramya, "The Real-Time Monitoring Of Water Quality In IoT Environment," in 2015 International Conference on Innovations in Information, Embedded and Communication Systems (ICIIECS), 2015: IEEE, pp. 1-5.

176. P. Brunner, H.-J. H. Franssen, L. Kgotlhang, P. Bauer-Gottwein, and W. Kinzelbach, "How Can Remote Sensing Contribute In Groundwater Modeling?," Hydrogeology journal, vol. 15, no. 1, pp. 5-18, 2007.

177. A. Kemna, J. Vanderborght, B. Kulessa, and H. Vereecken, "Imaging And Characterisation Of Subsurface Solute Transport Using Electrical Resistivity Tomography (Ert) And Equivalent Transport Models," Journal of Hydrology, vol. 267, no. 3-4, pp. 125146, 2002.

178. J. Dams, J. Dujardin, R. Reggers, I. Bashir, F. Canters, and O. Batelaan, "Mapping Impervious Surface Change From Remote Sensing For Hydrological Modeling," Journal of Hydrology, vol. 485, pp. 84-95, 2013.

179. P. Brunner, H. Li, W. Kinzelbach, W. Li, and X. Dong, "Extracting Phreatic Evaporation From Remotely Sensed Maps Of Evapotranspiration," Water Resources Research, vol. 44, no. 8, 2008.

180. P. Brunner, P. Bauer, M. Eugster, and W. Kinzelbach, "Using Remote Sensing To Regionalize Local Precipitation Recharge Rates Obtained From The Chloride Method," Journal of Hydrology, vol. 294, no. 4, pp. 241-250, 2004.

181. B. J. Choudhury, "Synergism Of Multispectral Satellite Observations For Estimating Regional Land Surface Evaporation," Remote Sensing of Environment, vol. 49, no. 3, pp. 264-274, 1994.

182. Y. Zhou, D. Dong, J. Liu, and W. Li, "Upgrading A Regional Groundwater Level Monitoring Network For Beijing Plain, China," Geoscience Frontiers, vol. 4, no. 1, pp. 127-138, 2013.

183. V. L. McGuire, "Water-Level And Recoverable Water In Storage Changes, High Plains Aquifer, Predevelopment To 2015 And 2013-15," US Geological Survey, 2328-0328, 2017.

184. M. Xiao et al., "How Much Groundwater Did California's Central Valley Lose During The 2012-2016 Drought?," Geophysical Research Letters, vol. 44, no. 10, pp. 4872-4879, 2017.

185. C. F. Brush, E. C. Dogrul, and T. N. Kadir, Development And Calibration Of The California Central Valley Groundwater-Surface Water Simulation Model (C2vsim), Version 3.02-Cg. Bay-Delta Office, California Department of Water Resources, 2013.

186. C. C. Faunt, K. Belitz, and R. T. Hanson, "Development Of A Three-Dimensional Model Of Sedimentary Texture In Valley-Fill Deposits of Central Valley, California, USA," Hydrogeology Journal, vol. 18, no. 3, pp. 625-649, 2010.

187. N. S. Reddy, M. S. Saketh, and S. Dhar, "Review Of Sensor Technology For Mine Safety Monitoring Systems: A Holistic Approach," in 2016 IEEE First International Conference on Control, Measurement and Instrumentation (CMI), 2016: IEEE, pp. 429-434.

188. D. Neyens, M. Baïsset, and H. Lovighi, "Monitoring The Groundwater Quality/Quantity From Your Desktop-Application To Salt Water Intrusion Monitoring EMI: Environmental data Management Interface," in E3S Web of Conferences, 2018, vol. 54: EDP Sciences, p. 00021.

189. J. Drage and G. Kennedy, "Building a Low-Cost, Internet-of-Things, Real-Time Groundwater Level Monitoring Network," Groundwater Monitoring E Remediation, vol. 40, no. 4, pp. 67-73, 2020.

190. A. Botta, W. De Donato, V. Persico, and A. Pescapé, "Integration Of Cloud Computing And Internet Of Things: A Survey," Future generation computer systems, vol. 56, pp. 684-700, 2016.

191. F. P. Sun J, Web GIS: Principles and Applications. ESRI Press, 2010.

192. S. Li, S. Dragicevic, and B. Veenendaal, Advances In Web-Based GIS, Mapping Services And Applications. CRC Press, 2011.

193. I. Heywood, S. Cornelius, and S. Carver, An Introduction To Geographical Information Systems. Harlow: Pearson Education Limited, 2011.

194. Z.-R. Peng and M.-H. Tsou, Internet GIS: Distributed Geographic Information Services For The Internet And Wireless Networks. John Wiley \& Sons, 2003.

195. I. Chenini and A. B. Mammou, "Groundwater Recharge Study In Arid Region: An Approach Using GIS Techniques And Numerical Modeling," Computers E Geosciences, vol. 36, no. 6, pp. 801-817, 2010.

196. C. Stefan and N. Ansems, "Web-Based Global Inventory Of Managed Aquifer Recharge Applications," Sustainable Water Resources Management, vol. 4, no. 2, pp. 153-162, 2018.

197. D. R. Maidment and S. Morehouse, "Arc Hydro: GIS For Water Resources," ESRI Inc., Redlands, 2002.

198. D. Jones, N. Jones, J. Greer, and J. Nelson, "A Cloud-Based MODFLOW Service For Aquifer Management Decision Support," Computers \& Geosciences, vol. 78, pp. 81-87, 2015. 
199. S. Balram and S. Dragicevic, "Collaborative Geographic Information Systems: Origins, Boundaries, And Structures," in Collaborative geographic information systems: IGI Global, 2006, pp. 1-23.

200. M. Werner, J. Schellekens, P. Gijsbers, M. van Dijk, O. van den Akker, and K. Heynert, "The Delft-FEWS Flow Forecasting System," Environmental Modelling \& Software, vol. 40, pp. 65-77, 2013.

201. Y.-C. Hsu, Y.-L. Chang, C.-H. Chang, J.-C. Yang, and Y.-K. Tung, "Physical-Based Rainfall-Triggered Shallow Landslide Forecasting," Smart Water, vol. 3, no. 1, pp. 1-16, 2018.

202. L. Foglia et al., "FREEWAT, A Free And Open Source, GIS-Integrated, Hydrological Modeling Platform," 2018.

203. R. Rossetto et al., "Integrating Free And Open Source Tools And Distributed Modelling Codes In GIS Environment For DataBased Groundwater Management," Environmental Modelling \& Software, vol. 107, pp. 210-230, 2018.

204. G. De Filippis et al., "Spatial Data Management and Numerical Modelling: Demonstrating the Application of the QGIS-Integrated FREEWAT Platform at 13 Case Studies for Tackling Groundwater Resource Management," Water, vol. 12, no. 1, p. 41, 2020 .

205. A. D. Snow et al., "A High-Resolution National-Scale Hydrologic Forecast System From A Global Ensemble Land Surface Model," JAWRA Journal of the American Water Resources Association, vol. 52, no. 4, pp. 950-964, 2016.

206. M. M. Morsy et al., "Design Of A Metadata Framework For Environmental Models With An Example Hydrologic Application In HydroShare," Environmental Modelling \& Software, vol. 93, pp. 13-28, 2017.

207. N. R. Swain et al., "A New Open Source Platform For Lowering The Barrier For Environmental Web App Development," Environmental Modelling E Software, vol. 85, pp. 11-26, 2016.

208. MAGNET. "MAGNET4water." https://www.magnet4water.com/ (accessed.

209. T. Malche and P. Maheshwary, "Internet Of Things (IoT) Based Water Level Monitoring System For Smart Village," in Proceedings of International Conference on Communication and Networks, 2017: Springer, pp. 305-312.

210. J. S. Horsburgh et al., "Hydroshare: Sharing Diverse Environmental Data Types And Models As Social Objects With Application To The Hydrology Domain," JAWRA Journal of the American Water Resources Association, vol. 52, no. 4, pp. 873-889, 2016.

211. E. A. Brewer, "Towards Robust Distributed Systems," in PODC, 2000, vol. 7, no. 10.1145: Portland, OR, p. 343477.343502.

212. H.-C. Hung, I.-F. Liu, C.-T. Liang, and Y.-S. Su, "Applying Educational Data Mining To Explore Students' Learning Patterns In The Flipped Learning Approach For Coding Education," Symmetry, vol. 12, no. 2, p. 213, 2020.

213. Y.-H. Lai, S.-Y. Chen, C.-F. Lai, Y.-C. Chang, and Y.-S. Su, "Study On Enhancing AIoT Computational Thinking Skills By Plot Image-Based Vr," Interactive Learning Environments, pp. 1-14, 2019.

214. W. M. Alley and S. A. Leake, "The journey from safe yield to sustainability," Groundwater, vol. 42, no. 1, pp. 12-16, 2004.

215. J. Bredehoeft and T. Durbin, "Groundwater Development-The Time to Full Capture Problem," Groundwater, vol. 47, no. 4, pp. 506-514, 2009.

216. E. Coppola, M. Poulton, E. Charles, J. Dustman, and F. Szidarovszky, "Application of Artificial Neural Networks to Complex Groundwater Management Problems," Natural resources research, vol. 12, no. 4, pp. 303-320, 2003

217. M. Saatsaz, M. Chitsazan, S. Eslamian, and W. N. A. Sulaiman, "The Application of Groundwater Modelling to Simulate the Behaviour of Groundwater Resources in the Ramhormooz Aquifer, Iran," International Journal of Water, vol. 6, no. 1-2, pp. 2942, 2011.

218. M. Huang and Y. Tian, "Prediction of Groundwater Level for Sustainable Water Management in an Arid Basin using Datadriven Models," in International Conference on Sustainable Energy and Environmental Engineering (SEEE), Bangkok, 2015.

219. W. G. Zhao, H. Wang, and Z. J. Wang, "Groundwater Level Forecasting Based on Support Vector Machine," in Applied Mechanics and Materials, 2011, vol. 44: Trans Tech Publ, pp. 1365-1369.

220. S. Sahoo, T. Russo, J. Elliott, and I. Foster, "Machine Learning Algorithms for Modeling Groundwater Level Changes in Agricultural Regions of the US," Water Resources Research, vol. 53, no. 5, pp. 3878-3895, 2017.

221. K. L. Lueth, "Why the Internet of Things is called the Internet of Things: Definition, History, Disambiguation," IoT Analytics, vol. 19, 2014

222. J. Romkey, "Toast of the IoT: The 1990 Interop Internet Toaster," IEEE Consumer Electronics Magazine, vol. 6, no. 1, pp. 116119, 2016.

223. G. D. Maayan, "The IoT Rundown for 2020: Stats, Risks, and Solutions," Security Today, vol. $13,2020$.

224. W.-Y. Wu et al., "Divergent Effects of Climate Change on Future Groundwater Availability in Key Mid-Latitude Aquifers," Nature Communications, vol. 11, no. 1, pp. 1-9, 2020.

225. F. T. Portmann, P. Döll, S. Eisner, and M. Flörke, "Impact of Climate Change on Renewable Groundwater Resources: Assessing the Benefits of Avoided Greenhouse Gas Emissions Using Selected CMIP5 Climate Projections," Environmental Research Letters, vol. 8, no. 2, p. 024023, 2013.

226. L. Konikow and J. Bredehoeft, "Groundwater Resource Development Effects and Sustainability; The Groundwater Project," ed, 2020.

227. H. Seyler, K. Witthüser, and M. Holland, "The Capture Principle Approach to Sustainable Groundwater Use Incorporating Sustainability Indicators and Decision Framework for Sustainable Groundwater Use," Water Research Commission: Pretoria, South Africa, 2016.

228. J. Van der Gun and A. Lipponen, "Reconciling Groundwater Storage Depletion Due to Pumping with Sustainability," Sustainability, vol. 2, no. 11, pp. 3418-3435, 2010.

229. S. Anumalla, B. Ramamurthy, D. C. Gosselin, and M. Burbach, "Groundwater Monitoring Using Smart Sensors," in 2005 IEEE International Conference on Electro Information Technology, 2005: IEEE, pp. 6 pp.-6. 
230. M. Afifi, M. F. Abdelkader, and A. Ghoneim, "An IoT System for Continuous Monitoring and Burst Detection in Intermittent Water Distribution Networks," in 2018 International Conference on Innovative Trends in Computer Engineering (ITCE), 2018: IEEE, pp. 240-247.

231. N. Kamaruidzaman and S. N. Rahmat, "Water Monitoring System Embedded with the Internet of Things (IoT) Device: A Review," in IOP Conference Series: Earth and Environmental Science, 2020, vol. 498, no. 1: IOP Publishing, p. 012068.

232. S. T. Prinos, A. Lietz, and R. Irvin, "Design of a Real-Time Ground-Water Level Monitoring Network and Portrayal of Hydrologic Data in Southern Florida," US Geological Survey, 2002

233. E. Mesquita et al., "Groundwater Level Monitoring Using a Plastic Optical Fiber," Sensors and Actuators A: Physical, vol. 240, pp. 138-144, 2016.

234. O. H. Kombo, S. Kumaran, and A. Bovim, "Design and Application of a Low-cost, Low-Power, LoRa-GSM, IoT Enabled System for Monitoring of Groundwater Resources with Energy Harvesting Integration," IEEE Access, 2021.

235. Q. Zhou et al., "Real-Time Management of Groundwater Resources Based on Wireless Sensors Networks," Journal of Sensor and Actuator Networks, vol. 7, no. 1, p. 4, 2018.

236. T. Robles et al., "An IoT Based Reference Architecture for Smart Water Management Processes," J. Wirel. Mob. Networks Ubiquitous Comput. Dependable Appl., vol. 6, no. 1, pp. 4-23, 2015.

237. F. Mao, K. Khamis, S. Krause, J. Clark, and D. M. Hannah, "Low-Cost Environmental Sensor Networks: Recent Advances and Future Directions," (in English), Frontiers in Earth Science, Mini Review vol. 7, no. 221, 2019-September-11 2019, doi: $10.3389 /$ feart.2019.00221.

238. K. Chan et al., "Low-Cost Electronic Sensors for Environmental Research: Pitfalls and Opportunities," Progress in Physical Geography: Earth and Environment, vol. 45, no. 3, pp. 305-338, 2021.

239. F. Tauro et al., "Measurements and Observations in the XXI century (MOXXI): Innovation and Multi-disciplinarity to Sense the Hydrological Cycle," Hydrological sciences journal, vol. 63, no. 2, pp. 169-196, 2018.

240. P. Verma et al., "Towards an IoT Based Water Management System for a Campus," in 2015 IEEE First International Smart Cities Conference (ISC2), 2015: IEEE, pp. 1-6.

241. Z. S. M. Odli et al., "Development of Portable Water Level Sensor for Flood Management System," ARPN Journal of Engineering and Applied Sciences, vol. 11, no. 8, pp. 5352-5357, 2016. 